\title{
Transition Metal-Catalyzed Asymmetric Reactions Using P-Chirogenic Diaminophosphine Oxides: DIAPHOXs
}

\author{
Tetsuhiro Nемото \\ Graduate School of Pharmaceutical Sciences, Chiba University; \\ 1-33 Yayoi-cho, Inage-ku, Chiba 263-8522, Japan. \\ Received May 29, 2008
}

\begin{abstract}
This review describes the development of a new class of chiral phosphorus ligands: amino acid-derived Pchirogenic diaminophosphine oxides, DIAPHOXs, and their application to several transition metal-catalyzed asymmetric allylic substitution reactions. Pd-catalyzed asymmetric allylic alkylation with cyclic $\beta$-keto esters as prochiral nucleophiles was initially examined using P-chirogenic diaminophosphine oxide 1a, resulting in highly enantioselective construction of quaternary stereocenters. Mechanistic investigations revealed that 1a is activated by $\mathrm{N}, \mathrm{O}$-bis(trimethylsilyl)acetamide-induced tautomerization to afford a trivalent diamidophosphite species $\mathbf{1 3}$, which functions as the actual ligand. Pd-catalyzed asymmetric allylic substitutions of both acyclic and cyclic substrates were also examined using various nucleophiles such as malonate derivatives, nitromethane, aliphatic amines, and aromatic amines, providing a variety of chiral compounds with good to excellent enantioselectivity. In addition, Ir-catalyzed asymmetric allylic amination and alkylation of terminal allylic carbonates were examined using structurally optimized P-chirogenic diaminophosphine oxides, and the corresponding branched products were obtained in a highly regio- and enantioselective manner. Furthermore, the developed catalytic asymmetric process was successfully applied to the catalytic enantioselective synthesis of biologically active compounds, $(R)$-preclamol, $(R)$-baclofen hydrochloride, and (-)-paroxetine.
\end{abstract}

Key words chiral ligand; diaminophosphine oxide; asymmetric catalysis; palladium; iridium; asymmetric allylic substitution

\section{Introduction}

Since the early 1970s, a variety of chiral ligands for transition metal-mediated asymmetric reactions have been developed. ${ }^{1)}$ From a functional point of view, one value of enantiomeric excess is that it is the simplest index for evaluating the ability of chiral ligands. On the other hand, from a practical point of view, air-stable, inexpensive, and easily accessible ligands are highly desirable. Secondary phosphine oxides and phosphonic acid derivatives are air- and moisture-stable pentavalent phosphorus compounds and exist in equilibrium between pentavalent forms $\left(\mathrm{RR}^{\prime} \mathrm{P}(=\mathrm{O}) \mathrm{H}\right)$ and trivalent tautomeric forms (RR'POH) (Chart 1). ${ }^{2)}$ This property allows for the use of these compounds as air- and moisture-stable ligands in transition metal catalysis. ${ }^{3-5)}$ Several secondary phosphine oxides and their equivalent have been successfully applied to Pt-catalyzed reactions, ${ }^{6,7)} \mathrm{Pd}$-catalyzed aromatic substitution reactions, ${ }^{8-10)} \mathrm{Pd}$ - and Ni-catalyzed cross coupling reactions, ${ }^{11-15)} \mathrm{Pd}$-catalyzed oxidative etherification of

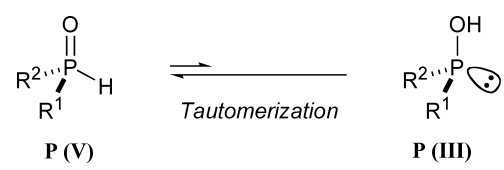

Chart 1. Tautomerization of Secondary Phosphine Oxides and Phosphonic Acid Derivatives aldehydes ${ }^{16)}$ and $\mathrm{Ru}$-catalyzed $\mathrm{C}-\mathrm{H}$ bond activation. ${ }^{17,18)}$

During the $\mathrm{P}(\mathrm{V})-\mathrm{P}(\mathrm{III})$ equilibrium, stereochemical arrangement around the phosphorus center is retained. This interesting property has inspired the creation of a new research field: asymmetric catalysis with P-chirogenic phosphine oxides. The first application of P-chirogenic secondary phosphine oxide to Ir-catalyzed asymmetric hydrogenation was reported by Minnaard, Feringa, and de Vries. ${ }^{19,20)}$ Pd-catalyzed asymmetric allylic alkylation ${ }^{21)}$ and asymmetric benzylidencyclopropanation $^{22}$ were also reported by Dai and Buono, respectively. Simple P-chirogenic secondary phosphine oxides, such as tert-butylphenylphosphine oxide, have been prepared by optical resolution ${ }^{23,24)}$ or separation of chiral chromatography. ${ }^{19)}$ A practical method for the asymmetric synthesis of various kinds of P-chirogenic secondary phosphine oxides, however, is not yet established. ${ }^{25)}$ Therefore the development of an efficient strategy to synthesize various Pchirogenic secondary phosphine oxides or their equivalent in an optically pure form is in high demand. We envisaged that this preparative drawback could be overcome by designing new ligands based on a chiral diamine framework, and finally succeeded in developing a new class of chiral phosphorus ligand. This review presents our recent research on transition metal-catalyzed asymmetric allylic substitution reactions ${ }^{26,27)}$ using amino acid-derived P-chirogenic diaminophosphine oxides: DIAPHOXs. ${ }^{28)}$ 


\section{Design and Synthesis of P-Chirogenic Diaminophos- phine Oxides: DIAPHOXs ${ }^{29)}$}

Cyclic diaminophosphine oxides with a stereogenic center on the phosphorus atom can be prepared from chiral (or achiral) asymmetric diamines. Separation of the diastereomeric (or enantiomeric) mixture, however, is necessary to obtain optically pure P-chirogenic diaminophosphine oxide. Our strategy to synthesize P-chirogenic diaminophosphine oxides is as follows: Triaminophosphines are reactive to water under acidic conditions via an $S_{N} 2$-type process, affording the corresponding diaminophosphine oxides through $\mathrm{P}(\mathrm{III})$ to $\mathrm{P}(\mathrm{V})$ tautomerization. Therefore we expected that diastereoselective formation of P-chirogenic triaminophosphine starting from optically active branched-triamines, followed by the introduction of oxygen functionality on the phosphorus atom, would be an efficient synthetic route (Chart 2).

Synthetic route for $\left(S, R_{\mathrm{P}}\right)$-DIAPHOX 1a is shown in Chart

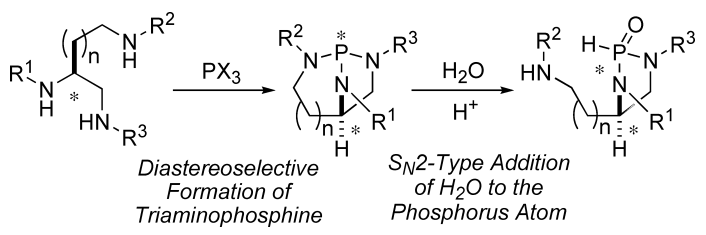

Chart 2. Strategy for the Synthesis of P-Chirogenic Diaminophosphine Oxides
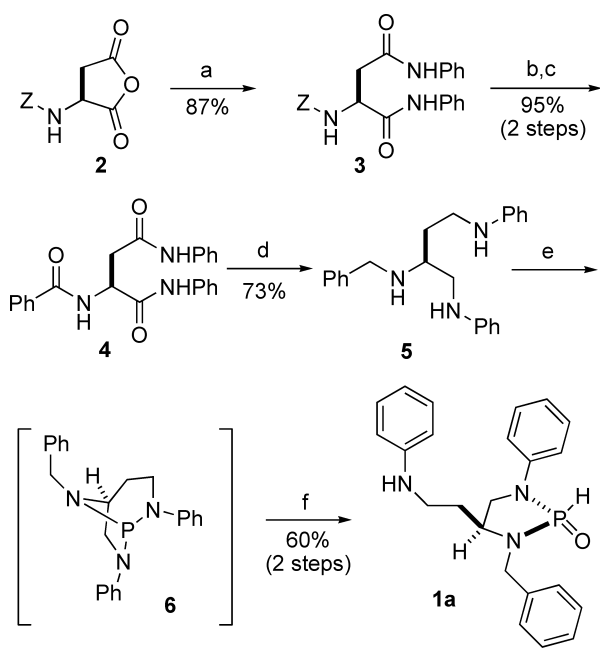

Conditions. (a) aniline, DMF, rt, then aniline, EDC, rt. (b) $\mathrm{Pd}-\mathrm{C}, \mathrm{H}_{2}(1 \mathrm{~atm}), 2$ propanol-DMF, rt. (c) benzoyl chloride, $\mathrm{NEt}_{3}$, THF, rt. (d) $\mathrm{LiAlH}_{4}$, THF, reflux. (e) $\mathrm{PCl}_{3}, \mathrm{NEt}_{3}$, toluene, $-78^{\circ} \mathrm{C}$ to rt. (f) $\mathrm{SiO}_{2}, \mathrm{H}_{2} \mathrm{O}$, AcOEt, rt.

Chart 3. Synthesis of $\left(S, R_{\mathrm{P}}\right)$-DIAPHOX 1a
3. Our synthesis started with the commercially available acid anhydride 2 , which can be easily prepared from $(S)$-aspartic acid. Nucleophilic opening of $\mathbf{2}$, followed by condensation with aniline in the presence of 1-ethyl-3-(3-dimethylaminopropyl)-carbodiimide (EDC), yielded the corresponding dianilide 3. Removal of a carbobenzyloxy $(Z)$ group, followed by amide formation with benzoyl chloride, afforded triamide 4. After reduction of all of the amide groups, the obtained triamine 5 was reacted with phosphorus trichloride to afford the corresponding triaminophosphine $\mathbf{6}$, which was converted into $\left(S, R_{\mathrm{P}}\right)$-DIAPHOX 1a by treatment with silica in wet ethyl acetate. Direct purification of the crude triaminophosphine residue with silica gel column chromatography could be utilized as a more convenient alternative method. Similarly, structurally modified aspartic acid-derived $\left(S, R_{\mathrm{P}}\right)$ DIAPHOXs $\mathbf{1 b}-\mathbf{h}$ could be prepared using the corresponding aromatic amines and acid chlorides (Fig. 1).

\section{Pd-Catalyzed Asymmetric Allylic Substitution Reac- tions Using Carbon Nucleophiles}

2.1. Asymmetric Allylic Alkylation of 1,3-Diphenylallyl Acetate with Dimethyl Malonate and Determination of the Actual Ligand Structure ${ }^{30)}$ With optically pure DIAPHOXs in hand, we attempted to use them as chiral ligands. We first examined Pd-catalyzed asymmetric allylic alkylation of 1,3-diphenylallyl acetate 7 with dimethyl malonate, because this reaction is recognized as the benchmark system to evaluate the ability of newly developed chiral ligands. Examinations were performed using $1 \mathrm{~mol} \%$ of $\left(\eta^{3}-\right.$ $\left.\mathrm{C}_{3} \mathrm{H}_{5} \mathrm{PdCl}\right)_{2}$ and $4 \mathrm{~mol} \%$ of $\left(S, R_{\mathrm{P}}\right)-\mathbf{1 a}$ in $\mathrm{CH}_{2} \mathrm{Cl}_{2}$. No reaction occurred when a variety of bases, such as $\mathrm{NaH}$, lithium diisopropylamide, 1,1,3,3-tetramethyguanidine, and diisopropylethylamine, were used. In contrast to other bases, $\mathrm{N}, \mathrm{O}$ bis(trimethysilyl)acetamide $(\mathrm{BSA})^{31)}$ promoted the reaction very efficiently to afford the corresponding product $(S)-\mathbf{8}$ in $94 \%$ yield and in $99 \%$ ee (Chart 4 ).

Very interestingly, typical bases other than BSA did not promote the reaction. ${ }^{31} \mathrm{P}-\mathrm{NMR}$ studies revealed that pentavalent 1a [chemical shift: $12.5 \mathrm{ppm}\left(\mathrm{CDCl}_{3}\right)$ ] first reacts with

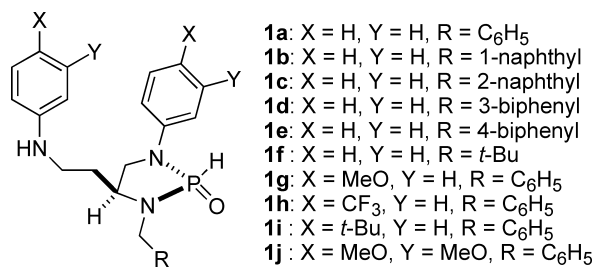

Fig. 1. Structure of Aspartic Acid-Derived $\left(S, R_{\mathrm{P}}\right)$-DIAPHOXs

Tetsuhiro Nemoto was born in Chiba, Japan, in 1976. He received his B.S. (1999), M.S. (2001), and Ph.D. (2005) degrees from the University of Tokyo under the direction of Prof. Masakatsu Shibasaki. In 2002, he also worked as a JSPS Research Fellow. In 2003, he started his academic career as an assistant professor in Prof. Yasumasa Hamada's group at Chiba University. He has received the Banyu Award in Synthetic Organic Chemistry (2004), Inoue Research Award for Young Scientists (2005), Daiichi-Sankyo Award in Synthetic Organic Chemistry (2007), and the Pharmaceutical Society of Japan Award for Young Scientists (2008). His current research interests include asymmetric catalysis and synthetic organic chemistry.

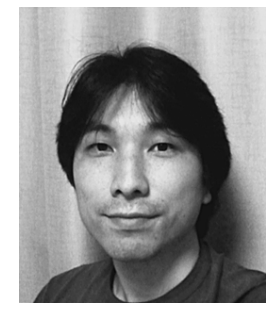

Tetsuhiro Nemoto 
BSA to provide a trivalent phosphorus compound [chemical shift: $\left.110.0 \mathrm{ppm}\left(\mathrm{CDCl}_{3}\right)\right]$. To clarify the structure of the observed trivalent species, several mechanistic experiments were performed. Preliminary experiments using diaminophosphine oxide 9 indicated that trivalent phosphorus compound $\mathbf{1 0}$ is formed in the presence of BSA (Fig. 2). This result was very informative for determining the structure of the diamidophosphite moiety of the trivalent species derived from 1a. To obtain experimental information on the structure of the nitrogen moiety on the sidearm of 1a, we performed fast atom bombardment mass spectrometry (FAB-MS) analysis (Fig. 2). FAB-MS analysis of the residue obtained from a $\mathrm{CH}_{2} \mathrm{Cl}_{2}$ solution of $1 \mathbf{a}$ and BSA (30 eq to 1a) exhibited a peak at $464 \mathrm{~m} / \mathrm{z}$. The detected peak corresponded to the molecular weight of 11. In addition, FAB-MS analysis of the residue obtained from a $\mathrm{CH}_{2} \mathrm{Cl}_{2}$ solution of $\left(\eta^{3}-\mathrm{C}_{3} \mathrm{H}_{5} \mathrm{PdCl}\right)_{2}$, 1a, and BSA in a ratio of $1: 2: 60$ exhibited a peak at 610 $\mathrm{m} / \mathrm{z}$. The detected peak corresponded to the molecular weight of the cationic complex 12. In addition, the observation that no trimethylsilylation of $\mathrm{N}$-methylaniline occurred in the presence of BSA suggested that the nitrogen atom on the sidearm in 1a is not silylated. On the basis of these results, we concluded that DIAPHOX 1a, the preligand, reacts with BSA in the reaction mixture, affording the trivalent phosphorus compound 13, which is proposed to be the actual ligand structure (Chart 5) (for more detailed discussions, see ref. 30).

2.2. Enantioselective Construction of All-Carbon Quaternary Stereocenter Using a Pd-DIAPHOX Catalyst System $^{29)}$ Catalytic enantioselective construction of a qua-

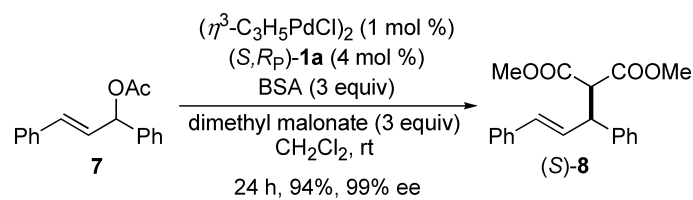

Chart 4. Pd-Catalyzed Asymmetric Allylic Alkylation of 7

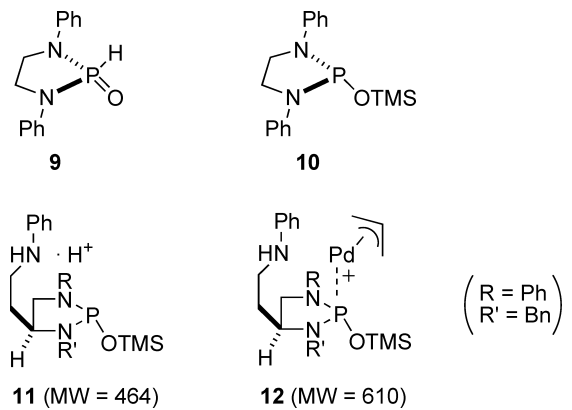

Fig. 2. Observed Species in the Preliminary Experiments and the FAB-MS Analysis

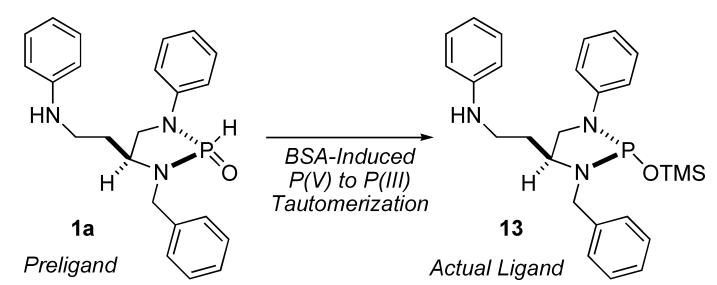

Chart 5. Actual Ligand Structure ternary carbon center is a formidable challenge in organic synthesis. ${ }^{32-35)} \mathrm{Pd}$-catalyzed asymmetric allylic substitution using prochiral nucleophiles is one of the most straightforward approaches toward this end. Few successful reactions of this type have been reported since the 1980s. ${ }^{36-44)}$ There were, however, several unsolved difficulties in substrate generality in each catalytic process, indicating that there is still room for developing a novel catalytic asymmetric process. These backgrounds led us to attempt this type of reaction using the Pd-DIAPHOX catalyst system. We first examined asymmetric allylic substitution of cinnamyl acetate 14a with ethyl 2-oxocyclohexane carboxylate 15a (Table 1). When the reaction was performed using $2.5 \mathrm{~mol} \%$ of $\left(\eta^{3}-\mathrm{C}_{3} \mathrm{H}_{5} \mathrm{PdCl}\right)_{2}$, $10 \mathrm{~mol} \%$ of $\left(S, R_{\mathrm{P}}\right)-\mathbf{1 a}$, and BSA as the base, $(S)-\mathbf{1 6 a}$ was obtained in $53 \%$ ee, even though the yield was only $10 \%$. Encouraged by this result, we investigated the effect of the addition of acetate salt. Detailed screening revealed that $\mathrm{Zn}(\mathrm{OAc})_{2}$ was the best additive for asymmetric induction. After several studies to determine the optimal amount of BSA and 15a, 4 eq of BSA and 1.5 eq of $15 \mathbf{a}$ to $14 \mathbf{a}$ gave the best reactivity (entry 8 ).

Having developed efficient conditions, we examined the scope and limitations of different substrates (Table 2). When $0.5-5 \mathrm{~mol} \%$ of the catalyst was employed, asymmetric allylic substitution of 14a using prochiral nucleophiles with six-, five-, seven-, and eight-membered rings proceeded smoothly at room temperature to provide the corresponding products in good yield with modest to high enantioselectivity (72-94\% ee) (entries $1-7)$. In addition to $\gamma$-aryl substituted-allyl acetates, $\gamma$-alkyl substituted-allyl acetates reacted with $\beta$-keto ester $\mathbf{1 5} \mathbf{g}$ to afford the corresponding products in good yield with good to high enantioselectivity $(80-92 \%$ ee) (entries 8-11). Reaction using simple allyl acetate, however, gave a less satisfactory result (entry 12). Particularly noteworthy is that $\gamma$-acetoxy $\alpha, \beta$-unsaturated carbonyl compounds are compatible with this reaction system. ${ }^{45)}$ With use of $2 \mathrm{~mol} \%$ of Pd catalyst and $4 \mathrm{~mol} \%$ of $\left(S, R_{\mathrm{P}}\right)-\mathbf{1 c}$, characteristic reaction adducts with three different carbonyl groups were obtained in excellent yield with high enantiomeric excess (up to $95 \%$ ee) (entries 13, 14).

2.3. Mechanistic Studies: Source of Enantioselection in Construction of Quaternary Stereocenters ${ }^{30}$ The sources of enantioselection are quite different between the two types of reactions examined: attack at enantiotopic termini of the meso- $\pi$-allyl complex (Chart 4 ) and differentia-

Table 1. Optimization of the Reaction Conditions

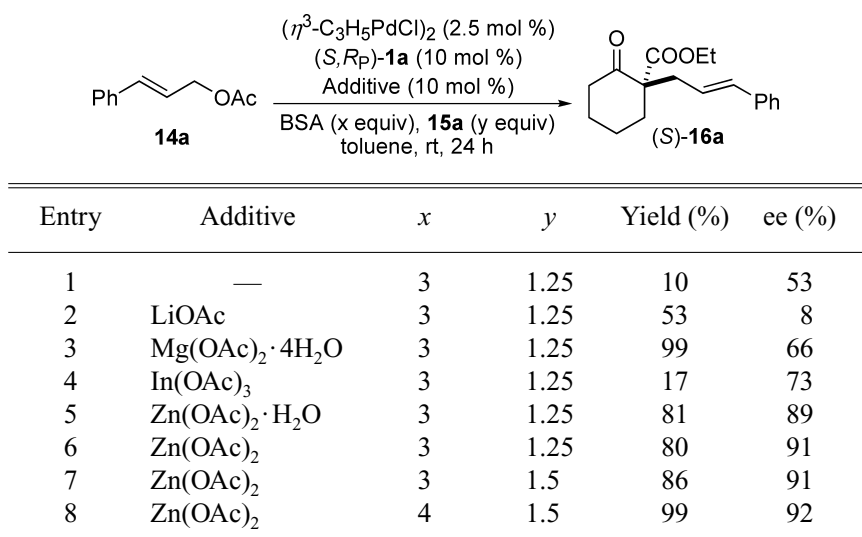


Table 2. Scope and Limitations

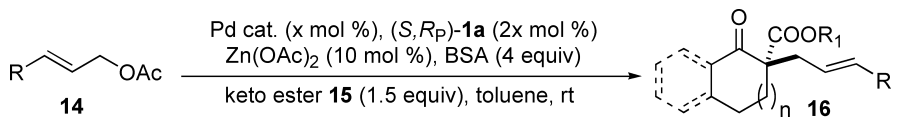

\begin{tabular}{|c|c|c|c|c|c|c|c|}
\hline Entry & Acetate & Keto ester & $x$ & Product & Time (h) & Yield (\%) & ee $(\%)$ \\
\hline 1 & 14a: $\mathrm{R}=\mathrm{Ph}$ & 15a: $n=1, \mathrm{R}^{1}=\mathrm{Et}$ & 2 & $16 a$ & 16 & 99 & $93(S)$ \\
\hline 2 & 14a: $\mathrm{R}=\mathrm{Ph}$ & 15a: $n=1, \mathrm{R}^{1}=\mathrm{Et}$ & 0.5 & $16 a$ & 32 & 85 & $93(S)$ \\
\hline 3 & 14a: $\mathrm{R}=\mathrm{Ph}$ & 15b: $n=1, \mathrm{R}^{1}=\mathrm{Me}$ & 2 & $16 \mathrm{~b}$ & 20 & 93 & 94 \\
\hline 4 & 14a: $\mathrm{R}=\mathrm{Ph}$ & 15c: $n=1, \mathrm{R}^{1}=\mathrm{Bn}$ & 2 & $16 c$ & 15 & 99 & $91(S)$ \\
\hline 5 & 14a: $\mathrm{R}=\mathrm{Ph}$ & 15d: $n=0, \mathrm{R}^{1}=\mathrm{Me}$ & 5 & 16d & 24 & 75 & $85(S)$ \\
\hline 6 & 14a: $\mathrm{R}=\mathrm{Ph}$ & 15e: $n=2, \mathrm{R}^{1}=\mathrm{Me}$ & 2 & $16 \mathrm{e}$ & 24 & 85 & 78 \\
\hline 7 & 14a: $\mathrm{R}=\mathrm{Ph}$ & 15f: $n=3, \mathrm{R}^{1}=\mathrm{Me}$ & 2 & $16 f$ & 20 & 97 & 72 \\
\hline 8 & 14b: $\mathrm{R}=4-\mathrm{Me}-\mathrm{C}_{6} \mathrm{H}_{5}$ & $15 \mathrm{~g}$ & 2 & $16 \mathrm{~g}$ & 10 & 98 & 92 \\
\hline 9 & $14 \mathrm{c}: \mathrm{R}=4-\mathrm{Cl}-\mathrm{C}_{6} \mathrm{H}_{5}$ & $15 g$ & 2 & $16 \mathrm{~h}$ & 7 & 99 & 91 \\
\hline 10 & 14d: $\mathrm{R}=\mathrm{CH}_{2} \mathrm{CH}_{2} \mathrm{Ph}$ & $15 g$ & 5 & $16 \mathbf{i}$ & 24 & 74 & 82 \\
\hline 11 & 14e: $\mathrm{R}=$ cyclohexyl & $15 \mathrm{~g}$ & 5 & $16 j$ & 20 & 83 & 80 \\
\hline 12 & 14g: $\mathrm{R}=\mathrm{H}$ & $15 \mathrm{~g}$ & 5 & $16 \mathrm{k}$ & 48 & 24 & $63(S)$ \\
\hline $13^{a)}$ & $14 \mathrm{~h}: \mathrm{R}=\mathrm{COO} t-\mathrm{Bu}$ & 15a: $n=1, \mathrm{R}^{1}=\mathrm{Et}$ & 2 & 161 & 24 & 99 & $95(S)$ \\
\hline $14^{a)}$ & 14i: $\mathrm{R}=\mathrm{COPh}$ & 15a: $n=1, \mathrm{R}^{1}=\mathrm{Et}$ & 2 & $16 \mathrm{~m}$ & 20 & 97 & $90(S)$ \\
\hline
\end{tabular}

a) $\left(S, R_{\mathrm{P}}\right)-1 \mathrm{c}$ was used as the ligand.

tion of the prochiral nucleophile face (Table 2). Despite the mechanistic difference, a high level of enantioselection was realized in both cases. Enantioselective nucleophilic attack of a stabilized prochiral anion to $\pi$-allylpalladium is not easy to control by the chiral ligand on the palladium atom, because the incoming nucleophile resides at the side opposite to the stereogenic center in the transition state. Interestingly, this difficult process proceeded with high enantioselectivity in the presence of $\mathrm{Zn}(\mathrm{OAc})_{2}$. To clarify the role of $\mathrm{Zn}(\mathrm{OAc})_{2}$ in the formation of quaternary stereocenters, we performed detailed mechanistic studies.

Considering the structure of $\mathbf{1 3}$, it is possible that $\mathbf{1 3}$ chelates to the Pd metal in a bidentate manner through both the phosphorus atom and the nitrogen atom. This led us to question whether this $\mathrm{Pd}$-ligand ratio $(\mathrm{Pd}: \mathbf{1 a}=1: 2)$ was optimal. To resolve this issue, we first investigated the Pd-ligand ratio using two representative reactions: 7 to 8 and 14a to 16a. The obtained results made a sharp contrast with those obtained using the optimal conditions. No reaction occurred in both cases using the catalyst prepared from the Pd source and $1 \mathrm{a}$ in a ratio of $1: 1$. In addition, there were positive nonlinear effects in both types of reactions. These results led us to hypothesize that the Pd-13 $(1: 2)$ complex exists in the reaction mixture, and might function as the catalytically active species. To elucidate the detailed reaction profiles, we performed kinetic experiments. The reaction rate of allylic alkylation of 7 with dimethyl malonate (Reaction Type A) had first-order dependency on the Pd catalyst, zero-order dependency on 7, and first-order dependency on dimethyl malonate. Similarly, the reaction rate of allylic substitution of $\mathbf{1 4 a}$ with 15a (Reaction Type B) had first-order dependency on the Pd catalyst, zero-order dependency on 14a, first-order dependency on 15a, and first-order dependency on $\mathrm{Zn}(\mathrm{OAc})_{2}$. The rate dependency on the Pd catalyst supports our expectation that two molecules of $\mathbf{1 3}$ chelate to the Pd metal and result in a positive nonlinear effect. Consequently, the $\operatorname{Pd}(0)$ complex $17(\mathrm{Pd}: 13=1: 2)$ is proposed to be the common active species (Fig. 3) (for more detailed discussions, see ref. 30).

Kinetic experiments also indicate that, in the case of Reaction Type $\mathrm{B}$, the rate-determining nucleophilic attack of the

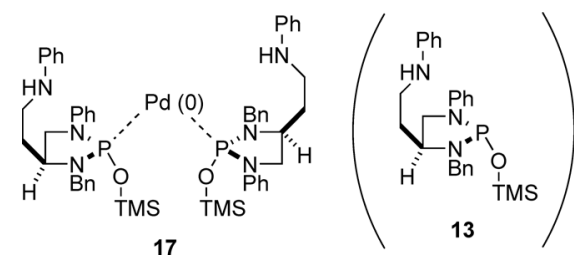

Fig. 3. Proposed Structure of the Catalytically Active Species

enol silyl ether, derived from 15a and BSA, to a cationic $\pi$ allylpalladium complex is achieved in cooperation with a single molecule of $\mathrm{Zn}(\mathrm{OAc})_{2}$. This suggestion led us to hypothesize that a nitrogen atom on the sidearm in $\mathbf{1 3}$ could fix the prochiral nucleophile in the appropriate position through a secondary ligand substrate interaction ${ }^{46,47)}$ mediated by $\mathrm{Zn}$ metal. To examine this possibility, we investigated the effect of ligand modifications (Table 3 ). When structurally modified diaminophosphine oxides $\left(S, R_{\mathrm{P}}\right)-\mathbf{1 8}-\mathbf{2 1}$ were used as the ligand, there were no significant changes in the stereoselectivity in the case of Reaction Type A (entries 1-5). In contrast, remarkable changes were observed in the case of Reaction Type B. Electronic and steric changes on the nitrogen atom (entries 8,9), as well as changes in the sidearm length (entry 10), influenced catalytic activity, resulting in decreased reactivity and selectivity. Particularly noteworthy is that there was a significant decrease in the enantioselectivity, when $\left(S, R_{\mathrm{P}}\right)-\mathbf{2 1}$, a ligand without a nitrogen atom on the sidearm, was used (entry 11). In addition, with the use of $\left(S, S_{\mathrm{P}}\right)$-22, opposite stereoselection was observed in Reaction Type A (entry 6). Moreover, no reaction occurred when $\left(S, S_{\mathrm{P}}\right)-\mathbf{2 2}$ was used in Reaction Type B (entry 12). These results clearly indicate that the ligand structure with a sidearm possessing a nitrogen atom is very important to achieve the present asymmetric catalysis. These findings led us to conclude that the secondary ligand substrate interaction mediated by $\mathrm{N}-\mathrm{Zn}$ coordination has a crucial role on the enantiofacial recognition of prochiral nucleophiles in Reaction Type B.

To obtain more detailed structural information for discussion on the sources of enantioselection, we tried crystallizing 
Table 3. Effect of Ligand Modification

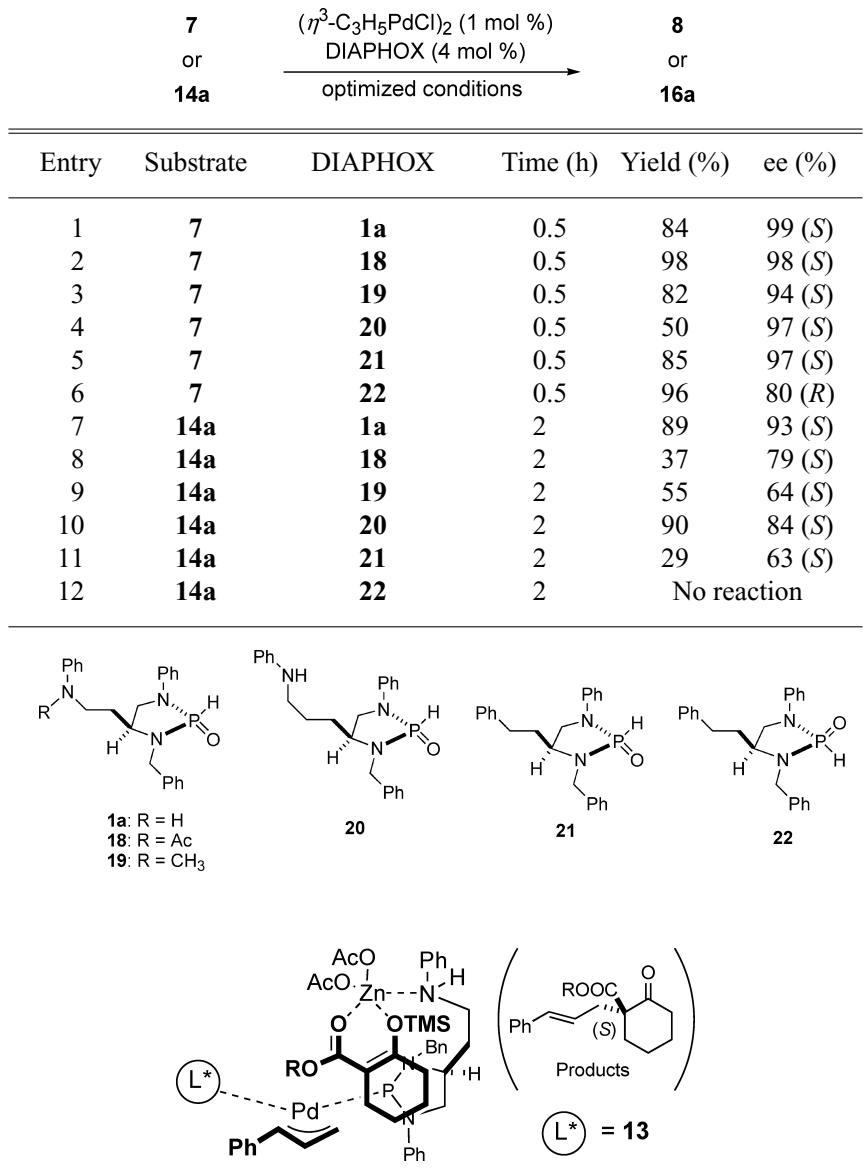

Fig. 4. Working Model

the catalyst species. Unfortunately, a crystal for X-ray analysis could not be obtained. Although the complete transition state is not clear, the enantioselection in Reaction Type B would be explained by the working model shown in Fig. 4 . The observed absolute configurations of 16a and other products indicate that the $\mathrm{C}-\mathrm{C}$ bond formation occurs on the $\mathrm{Si}$ face of the enolate nucleophile. The observation that nucleophiles with a smaller methyl ester gave higher enantioselectivities suggests that the ester moiety of the nucleophiles is located inside the chiral pocket. This spatial arrangement is stabilized through the Zn-mediated secondary ligand substrate interaction. Effective fixation of the three reactants results in not only an increase in the enantiofacial discrimination of nucleophiles, but also an enhancement of the reactivity.

2.4. Asymmetric Allylic Alkylation Using Nitromethane as the Nucleophile ${ }^{49}$ ) Various stabilized carbon nucleophiles are applicable to Pd-catalyzed asymmetric allylic alkylation. There are, however, only a few reports of Pdcatalyzed asymmetric allylic alkylation using nitronate nucleophiles, perhaps due to multiple alkylations and the formation of side products. ${ }^{49-52)}$ In our experiments, catalytic asymmetric allylic alkylation of 1,3-diphenylallyl ethyl carbonate 23 with nitromethane was performed using similar conditions to those of asymmetric allylic alkylation with dimethyl malonate (reaction conditions in Chart 4), giving the desired product $\mathbf{2 4}$ in only $5 \%$ yield and $66 \%$ ee, accompanied by the formation of some other side products. Although

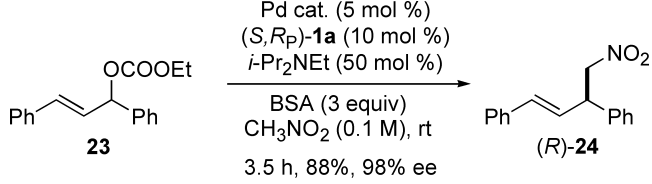

Chart 6. Pd-Catalyzed Asymmetric Allylic Alkylation with Nitromethane
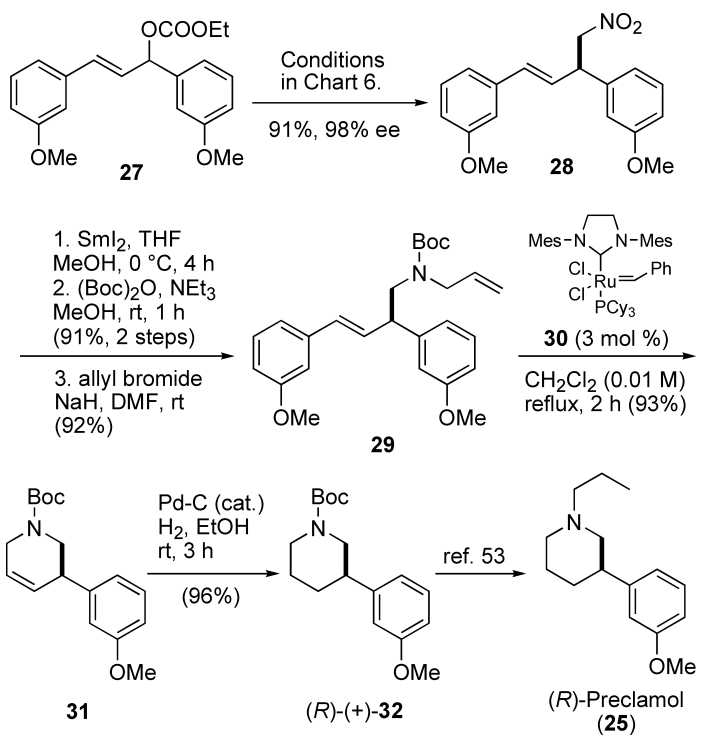

Chart 7. Enantioselective Synthesis of $(R)$-Preclamol

the chemical yield was low, there was a significant improvement in the enantioselectivity when nitromethane was used as the solvent ( $4 \mathrm{~h}, 26 \%$ yield, $96 \%$ ee). This result encouraged us to optimize the reaction in nitromethane. Silyl nitronates are efficiently generated from nitroalkanes in the presence of BSA and amine. Therefore the addition of amine to the reaction was examined in detail. We were pleased to find that catalytic amounts of $N, N$-diisopropylethylamine improved the chemical yield dramatically ( $88 \%$ yield) and there was a slight increase in the enantiomeric excess ( $98 \%$ ee) (Chart 6).

The present reaction system was successfully applied to the catalytic asymmetric synthesis of $(R)$-preclamol $[(+)-3$ PPP] (25), a selective dopamine $\mathrm{D}_{2}$ autoreceptor agonist, and $(R)$-baclofen hydrochloride (26), a $\mathrm{GABA}_{\mathrm{B}}$ receptor agonist. The synthetic route of enantioselective synthesis of $(R)$ preclamol is outlined in Chart 7. Pd-catalyzed asymmetric allylic substitution of $\mathbf{2 7}$ with nitromethane proceeded under the optimized conditions to afford $\mathbf{2 8}$ in $91 \%$ yield with $98 \%$ ee. Reduction of the nitro group with $\mathrm{SmI}_{2}$, followed by protection of the resulting amine with a Boc group and allylation, gave 29. Subsequently, 29 was treated with $3 \mathrm{~mol} \%$ of the Grubbs catalyst (30) to afford the corresponding cyclic product 31, which was successfully transformed into a chiral piperidine intermediate $(R)-(+)-32$. The known intermediate 32 can be converted into $(R)$-preclamol (25) using the reported procedure. ${ }^{53,54)}$ The synthetic route of enantioselective synthesis of $(R)$-baclofen hydrochloride is also outlined in Chart 8. Pd-catalyzed asymmetric allylic substitution of $\mathbf{3 3}$ with nitromethane proceeded under the optimized conditions to afford 34 in $92 \%$ yield with $97 \%$ ee. 34 was transformed into 35 using the same method as in the case of 28. After for- 
mation of enamide 36 using Pd-catalyzed vinyl transfer reaction, ${ }^{55}$ ring-closing metathesis was performed in the presence of 30, affording cyclic compound 37. Introduction of a hydroxyl group followed by oxidation of the resulting crude lactamol with PCC gave the known lactam $(R)-(+)-38$. The obtained lactam could be transformed into $(R)$-baclofen hydrochloride (26) using the reported procedure. ${ }^{56-59)}$

2.5. Asymmetric Allylic Alkylation of 2-Phenyl Cycloalkenyl Carbonates $^{60)}$ There are many reports of asymmetric allylic substitution using simple cycloalkenyl alcohol derivatives as substrates. Only limited success of asymmetric allylic substitution of 2-substituted cycloalkenyl alcohol derivatives, however, has been reported so far. ${ }^{61-68)}$ The success of the asymmetric allylic alkylation of 1,3-diphenylallyl acetate led us to examine asymmetric allylic alkylation of 2substituted cycloalkenyl alcohol derivatives using the Pd-DIAPHOX catalyst system. We first optimized the reaction conditions using asymmetric allylic alkylation of 2-phenylcyclohexenyl carbonate 39 with malonate nucleophiles (Table 4). Using $2.5 \mathrm{~mol} \%$ of $\left[\eta^{3}-\mathrm{C}_{3} \mathrm{H}_{5} \mathrm{PdCl}\right]_{2}$ and $10 \mathrm{~mol} \%$ of $\left(S, R_{\mathrm{P}}\right)-$
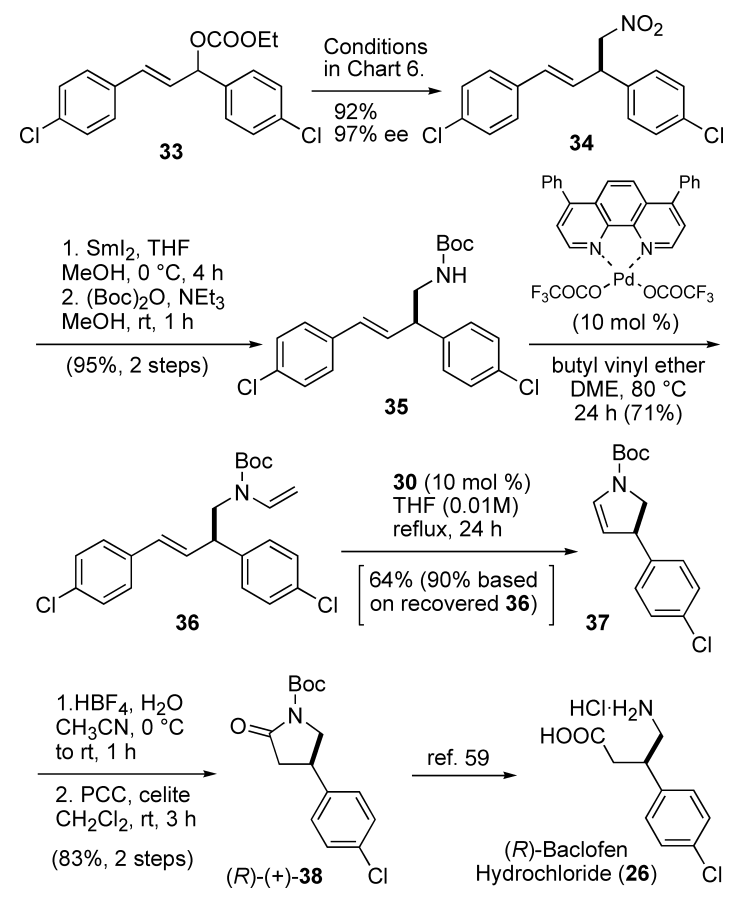

Chart 8. Enantioselective Synthesis of $(R)$-Baclofen Hydrochloride 1a in $\mathrm{CH}_{3} \mathrm{CN}$, the reaction proceeded slowly at room temperature to afford product 41 in $43 \%$ yield and $68 \%$ ee. To improve the reactivity and enantioselectivity, we investigated the effect of the additive in detail. Both reactivity and enantioselectivity were remarkably affected by the addition of acetate salts, and LiOAc was the best additive for both reactivity and enantioselectivity (entry 2). Further optimization of the ester substituents of a malonate nucleophile indicated that dibenzyl malonate resulted in the best enantioselectivity (entry 7). When a lithium enolate prepared from dibenzyl malonate and $\mathrm{LiH}$ was used as the nucleophile, 42 was obtained in $99 \%$ yield with $86 \%$ ee. This result indicates that LiOAc is likely related to the generation of lithium enolate in situ, resulting in increased enantioselectivity. 2-Phenyl-substituted cyclopentenyl carbonate $\mathbf{4 0}$ was also applicable to this reaction, and the corresponding product $\mathbf{4 3}$ was obtained in $92 \%$ yield with $89 \%$ ee (entry 8 ).

2.6. Pd-Catalyzed Enantioselective Synthesis of Quaternary $\alpha$-Amino Acid Derivatives Using Chiral Diaminophosphine Oxides ${ }^{69)}$ Pd-catalyzed asymmetric allylic substitution using $\beta$-keto esters with a nitrogen functional group at the $\alpha$-carbon as the prochiral nucleophiles is one of the most straightforward approaches for synthesizing chiral quaternary $\alpha$-amino acid derivatives. ${ }^{70-86)}$ Although several types of Pd-catalyzed asymmetric allylic substitutions using prochiral nucleophiles have been investigated since the 1980 s, there are only a few reports of asymmetric synthesis of such tetrasubstituted carbons using this strategy. ${ }^{87-91)}$

We first examined asymmetric allylic substitution of 14a with $\alpha$-acetoamido $\beta$-keto ester 44a based on the reaction conditions using cyclic $\beta$-keto ester nucleophiles (Table 5). There was a slight decrease in enantioselectivity, however, when $10 \mathrm{~mol} \%$ of $\mathrm{Zn}(\mathrm{OAc})_{2}$ was used as the additive (entry 1 $v s$. entry 2). We then investigated the effect of the structure of DIAPHOX under additive-free conditions. When the reaction was performed using $(S)$-aspartic acid-derived DIAPHOXs, there was no remarkable increase in the enantioselectivity (entries 2-8). Further studies revealed that enantioselectivity was improved when the reaction was performed using DIAPHOXs prepared from other amino acids. Finally, $\left(S, R_{\mathrm{P}}\right)-47$, prepared from $(S)$-phenylalanine, was best for asymmetric induction, affording $(R)-\mathbf{4 5 a}$ in $98 \%$ yield with $92 \%$ ee (entry 11 ). Further optimization of the reaction conditions revealed that $10 \mathrm{~mol} \%$ of KOAc dramatically increased reactivity (entry 12 ).

Table 4. Pd-Catalyzed Asymmetric Allylic Alkylation of 2-Phenyl Cycloalkenyl Carbonates

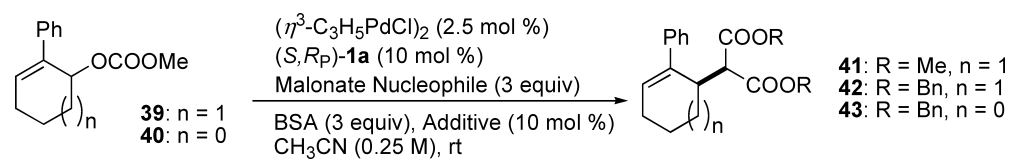

\begin{tabular}{|c|c|c|c|c|c|c|c|}
\hline Entry & Substrate & Nucleophile & Additive & Product & Time (h) & Yield (\%) & ee $(\%)$ \\
\hline 1 & 39 & $\mathrm{CH}_{2}(\mathrm{COOMe})_{2}$ & - & 41 & 48 & 43 & 68 \\
\hline 2 & 39 & $\mathrm{CH}_{2}(\mathrm{COOMe})_{2}$ & LiOAc & 41 & 4 & 94 & 80 \\
\hline 3 & 39 & $\mathrm{CH}_{2}(\mathrm{COOMe})_{2}$ & $\mathrm{NaOAc}$ & 41 & 4 & 95 & 67 \\
\hline 4 & 39 & $\mathrm{CH}_{2}(\mathrm{COOMe})_{2}$ & KOAc & 41 & 4 & 93 & 66 \\
\hline 5 & 39 & $\mathrm{CH}_{2}(\mathrm{COOMe})_{2}$ & $\mathrm{Mg}(\mathrm{OAc})_{2}$ & 41 & 96 & 55 & 80 \\
\hline 6 & 39 & $\mathrm{CH}_{2}(\mathrm{COOMe})_{2}$ & $\mathrm{Zn}(\mathrm{OAc})_{2}$ & 41 & 96 & 40 & 81 \\
\hline 7 & 39 & $\mathrm{CH}_{2}(\mathrm{COOBn})_{2}$ & $\mathrm{LiOAc}$ & 42 & 4 & 94 & $86(R)$ \\
\hline 8 & 40 & $\mathrm{CH}_{2}(\mathrm{COOBn})_{2}$ & LiOAc & 43 & 4 & 92 & $89(R)$ \\
\hline
\end{tabular}


The scope and limitations of different substrates were further examined under optimized conditions (Table 6). Asymmetric allylic substitutions using $N$-acyl-protected alkyl ketone-type substrates $44 \mathbf{a}-\mathbf{f}$ proceeded smoothly in the presence of KOAc, affording the corresponding quaternary $\alpha$ amino acid derivatives $\mathbf{4 5 a}-\mathbf{f}$ in excellent yield with high enantioselectivity ( $86-92 \%$ ee) (entries $1-6)$. The reaction adducts were highly crystalline compounds and the optical purity was efficiently enriched by a single recrystallization (entry 1). The present reaction conditions were also effective in asymmetric allylic substitution using carbamate-type substrates $\mathbf{4 4 \mathrm { g }}$ and $\mathbf{4 4 \mathrm { h }}$. The corresponding products $\mathbf{4 5 \mathrm { g }}$ and 45h were obtained in excellent yield with high enantioselectivity (entries 7,8 ). In contrast, no reaction occurred under

Table 5. Optimization of the Reaction Conditions

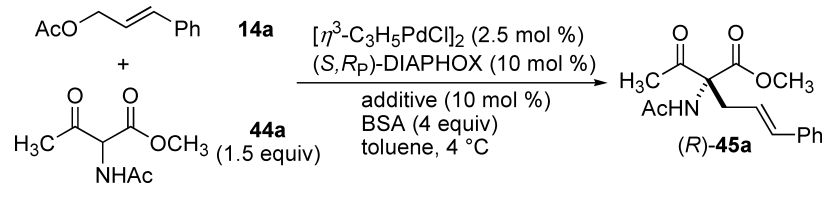

\begin{tabular}{cccccc}
\hline \hline Entry & DIAPHOX & Additive & Time (h) & Yield (\%) & ee (\%) \\
\hline 1 & $\mathbf{1 a}$ & Zn(OAc) & 48 & 96 & 74 \\
2 & $\mathbf{1 a}$ & - & 48 & 90 & 78 \\
3 & $\mathbf{1 b}$ & - & 60 & 23 & 51 \\
4 & $\mathbf{1 c}$ & - & 48 & 94 & 78 \\
5 & $\mathbf{1 g}$ & - & 48 & 90 & 79 \\
6 & $\mathbf{1 h}$ & - & 48 & 36 & 79 \\
7 & $\mathbf{1 i}$ & - & 20 & 99 & 69 \\
8 & $\mathbf{1 j}$ & - & 48 & 49 & 77 \\
9 & $\mathbf{2 0}$ & - & 48 & 95 & 88 \\
10 & $\mathbf{4 6}$ & - & 60 & 60 & 78 \\
11 & $\mathbf{4 7}$ & - & 24 & 98 & 92 \\
12 & $\mathbf{4 7}$ & KOAc & 12 & 99 & 90 \\
\hline
\end{tabular}

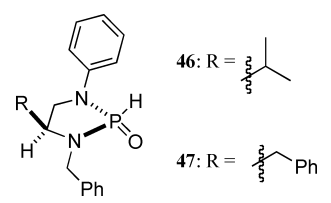

the same reaction conditions when phenyl ketone-type substrate 44i was used as the prochiral nucleophile. This problem could be overcome by the addition of KOAc (10 mol\%) and $\mathrm{KCl}(10 \mathrm{~mol} \%)$, and the corresponding product $45 \mathbf{i}$ was obtained in $99 \%$ yield with $80 \%$ ee (entry 9 ).

\section{Pd-Catalyzed Asymmetric Allylic Substitution Reac- tions Using Nitrogen Nucleophiles}

Considerable effort has been directed toward the catalytic asymmetric synthesis of $\alpha$-chiral amines because chiral amine units are ubiquitous in biologically active compounds. A transition metal-catalyzed asymmetric allylic amination is one of the most useful methods for synthesizing chiral allylic amines. ${ }^{92)}$ Several transition metal-catalyzed asymmetric allylic aminations using $\mathrm{Pd},{ }^{93-99)} \mathrm{Ir}^{100}{ }^{100}$ or other transition metal catalysts ${ }^{101,102)}$ have been reported. The success of the asymmetric allylic substitution reactions with carbon nucleophiles led us to examine asymmetric allylic amination using the Pd-DIAPHOX catalyst system.

3.1. Pd-Catalyzed Asymmetric Allylic Amination of Linear Substrates ${ }^{103)}$ We first examined asymmetric allylic amination of 1,3-diphenylallyl acetate 7 with benzylamine using $\left(S, R_{\mathrm{P}}\right)-\mathbf{1 a}$. The reaction was performed under conditions similar to the case of asymmetric allylic alkylation of 7 with dimethyl malonate, and the corresponding product $(R)-48$ a was obtained in $91 \%$ yield with $98 \%$ ee (Table 7, entry 1). Various amine nucleophiles were applied to this type of asymmetric allylic amination. Using 1$2 \mathrm{~mol} \%$ of Pd catalyst and $2-4 \mathrm{~mol} \%$ of $\left(S, R_{\mathrm{P}}\right)-\mathbf{1 a}$, asymmetric allylic amination of 7 with both primary and secondary amines proceeded at room temperature to give the corresponding products in good yield with high stereoselectivity. No reaction, however, occurred when $p$-anisidine was utilized as the nucleophile (entries 6,7). This catalyst system was also applied to asymmetric allylic amination of 1,3-dialkyl-substituted allyl carbonate 49 . The reaction was performed using $\left(S, R_{\mathrm{P}}\right)-\mathbf{1 a}$ in $\mathrm{CH}_{3} \mathrm{CN}$, affording the corresponding product 50 in moderate yield with low enantiomeric excess. There was a slight improvement in the enantioselectivity when $\left(S, R_{\mathrm{P}}\right)$-1b was used (entries 8,9$)$.

Table 6. Scope and Limitations

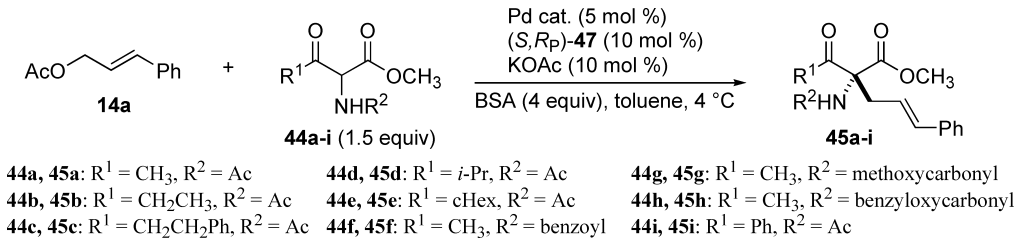

\begin{tabular}{ccccc}
\hline \hline Entry & Nucleophile & Time (h) & Yield (\%) & ee (\%) \\
\hline 1 & $\mathbf{4 4 a}$ & 12 & $99(70)^{a)}$ & $90(99)^{b)}(R)$ \\
2 & $\mathbf{4 4 b}$ & 24 & 98 & 87 \\
3 & $\mathbf{4 4 c}$ & 24 & 99 & 90 \\
4 & $\mathbf{4 4 d}$ & 48 & 99 & 86 \\
5 & $\mathbf{4 4 e}$ & 48 & 99 & 82 \\
6 & $\mathbf{4 4 f}$ & 20 & $73(99)^{c)}$ & $89(90)^{c)}$ \\
7 & $\mathbf{4 4 g}$ & $60(24)^{c)}$ & 99 & 89 \\
8 & $\mathbf{4 4 h}$ & 60 & No reaction $(99)^{c)}$ & $-(80)^{c)}$ \\
\hline
\end{tabular}

a) Yield of recrystallization from EtOH. b) Enantiomeric excess after single recrystallization from EtOH. c) $10 \mathrm{~mol} \%$ of $\mathrm{KOAc}$ and $10 \mathrm{~mol} \%$ of $\mathrm{KCl}$ were used as the additive. 
Table 7. Pd-Catalyzed Asymmetric Allylic Amination of 1,3-Disubstituted Allyl Alcohol Derivatives

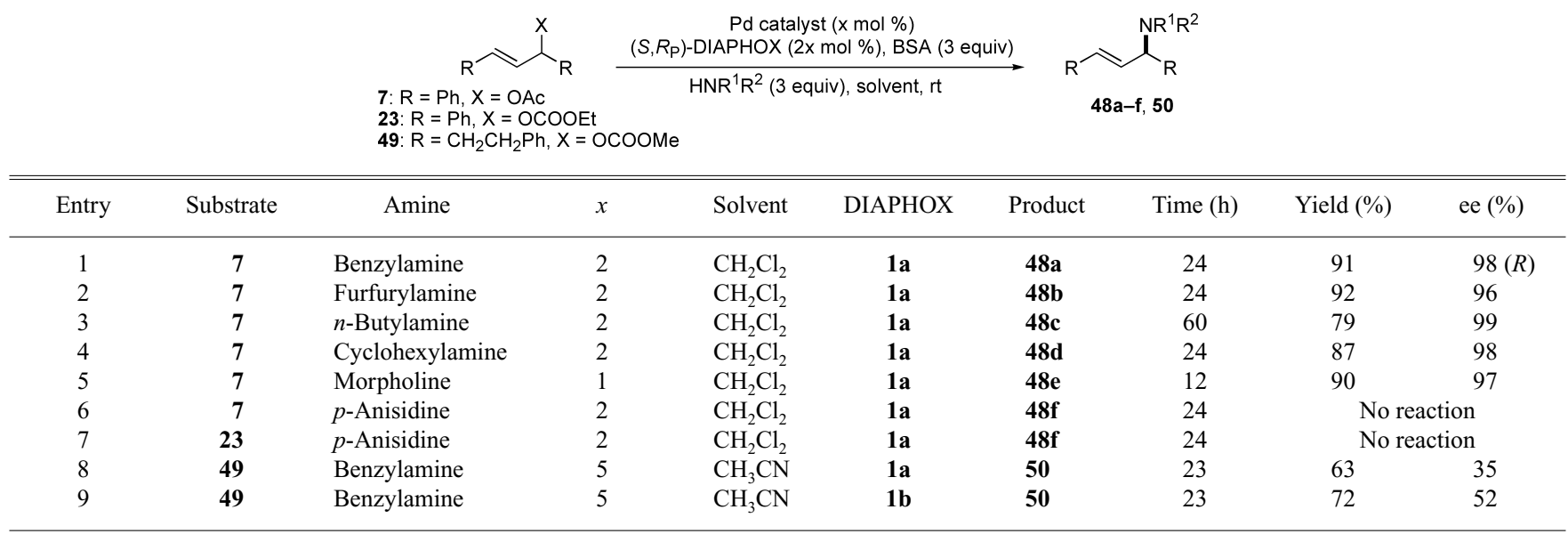

Table 8. Pd-Catalyzed Asymmetric Allylic Amination of 2-Substituted Cycloalkenyl Carbonates

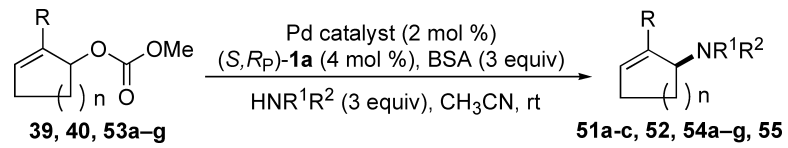

\begin{tabular}{|c|c|c|c|c|c|c|c|c|}
\hline Entry & $\mathrm{R}$ & $n$ & Substrate & Amine & Product & Time (h) & Yield (\%) & ee $(\%)$ \\
\hline 1 & $\mathrm{Ph}$ & 2 & 39 & Benzylamine & $51 \mathrm{a}$ & 17 & 93 & 96 \\
\hline 2 & $\mathrm{Ph}$ & 2 & 39 & $\mathrm{EtOOCCH}_{2} \mathrm{NH}_{2}$ & $51 \mathrm{~b}$ & 48 & 88 & $96(S)$ \\
\hline 3 & $\mathrm{Ph}$ & 2 & 39 & Morpholine & $51 \mathrm{c}$ & 7 & 90 & 97 \\
\hline 4 & $\mathrm{Ph}$ & 1 & 40 & Benzylamine & 52 & 8 & 99 & 93 \\
\hline $5^{a)}$ & $\mathrm{Ph}$ & 3 & $53 a$ & Benzylamine & $54 a$ & 3 & 84 & 83 \\
\hline 6 & $4-\mathrm{F}-\mathrm{C}_{6} \mathrm{H}_{4}$ & 2 & 53b & Benzylamine & $54 b$ & 5 & 95 & 93 \\
\hline $7^{a)}$ & $3-\mathrm{MeO}-\mathrm{C}_{6} \mathrm{H}_{4}$ & 2 & $53 \mathrm{c}$ & Benzylamine & $54 \mathrm{c}$ & 4 & 93 & 93 \\
\hline 8 & $2-\mathrm{F}-\mathrm{C}_{6} \mathrm{H}_{4}$ & 2 & 53d & Benzylamine & $54 d$ & 7 & 83 & 98 \\
\hline $9^{a)}$ & TBSO & 2 & $53 e$ & Benzylamine & $54 \mathrm{e}$ & 4 & 95 & 72 \\
\hline 10 & $\mathrm{Ph} \leadsto$ & 2 & $53 \mathrm{f}$ & Benzylamine & $54 \mathrm{~g}$ & 24 & 55 & 94 \\
\hline 11 & $\mathrm{Ph}=$ & 2 & $53 \mathrm{~g}$ & Benzylamine & $54 \mathrm{~g}$ & 24 & 75 & 80 \\
\hline 12 & $\mathrm{Ph}$ & 2 & 39 & $p$-Anisidine & 55 & 24 & Trace & - \\
\hline
\end{tabular}

a) $5 \mathrm{~mol} \%$ of Pd catalyst and $10 \mathrm{~mol} \%$ of $\left(S, R_{\mathrm{P}}\right)-1$ a were used.

3.2. Pd-Catalyzed Asymmetric Allylic Amination of Cyclic Substrates ${ }^{103)}$ The satisfactory results in the reaction system using a conventional substrate led us to examine asymmetric allylic amination of cyclic substrates. Asymmetric allylic amination of 2-substituted cycloalkenyl alcohol derivatives affords versatile adducts for the synthesis of nitrogen-containing natural products. Despite its usefulness, the success of this type of reaction is limited. ${ }^{63-66)}$ Although no reaction occurred when 2-phenylcyclohexenyl acetate was used as the substrate, allylic amination of 2-phenylcyclohexenyl carbonate 39 with benzylamine proceeded in $\mathrm{CH}_{2} \mathrm{Cl}_{2}$ using $2 \mathrm{~mol} \%$ of the catalyst, affording the corresponding product 51a in $75 \%$ yield and $93 \%$ ee. Examination of the solvent effect revealed that the reaction medium dramatically affected reactivity rather than enantioselectivity, and best results were obtained when $\mathrm{CH}_{3} \mathrm{CN}$ was used as the solvent (Table 8 , entry 1). ${ }^{104)}$

The scope and limitations of different substrates were further examined under optimized conditions (Table 8). As shown in entries $1-3$, asymmetric allylic amination of 2phenyl cyclohexenyl carbonates using primary and secondary amines proceeded at room temperature to provide the corre- sponding products in good yield with high enantioselectivity. Other cyclic substrates with a five-membered ring or a sevenmembered ring were also applicable to this reaction, affording chiral allylic amines with $93 \%$ or $83 \%$ ee, respectively (entries 4, 5). Asymmetric allylic amination of cyclohexenyl carbonates with various substituents at the 2-position was also examined using benzylamine as the nucleophile (entries 6-11). Aryl groups with an electron-withdrawing functional group, as well as an electron-donating functional group, were tolerant to this reaction, giving products with high enantioselectivity. Furthermore, substrates with alkyl, alkenyl, or alkynyl substituents were also applicable to this reaction, and the corresponding products were obtained in moderate to good enantiomeric excess. Asymmetric allylic amination of 39 with $p$-anisidine as the nucleophile, however, gave unsatisfactory results (entry 12).

We applied this catalyst system to the catalytic asymmetric synthesis of $(S)$-56, which is the key intermediate for Mori's total synthesis of crinine-type alkaloids (Chart 9). ${ }^{105)}$ Using $5 \mathrm{~mol} \%$ of Pd catalyst and $10 \mathrm{~mol} \%$ of $\left(S, R_{\mathrm{p}}\right)-\mathbf{1 a}$, asymmetric allylic amination of $\mathbf{5 7}$ with amine $\mathbf{5 8}$ proceeded at room temperature, affording the chiral allylic amine $\mathbf{5 9}$ in $98 \%$ 
yield and $97 \%$ ee, which could be converted to the key intermediate $(S)-\mathbf{5 6}$.

3.3. Enantioselective Synthesis of aza-Morita-BaylisHillman Reaction Products Using Asymmetric Allylic Amination ${ }^{106)}$ The catalytic enantioselective aza-MoritaBaylis-Hillman (aza-MBH) reaction provides functionalized chiral allylic amines. ${ }^{107)}$ To date, several asymmetric catalysts for this reaction have been developed. The scope of those asymmetric catalysts, however, is limited in intermolecular aza-MBH reactions. ${ }^{108-115)}$ There are no reports of a catalytic asymmetric intramolecular aza-MBH reaction. Pd-catalyzed asymmetric allylic amination of cycloalkenyl carbonates with an electron-withdrawing group at the 2-position is an alternative to the intramolecular aza-MBH reaction via nucleophilic catalysis. Although this type of transformation using oxygen nucleophiles has been investigated in detail by Trost et al. ${ }^{67,68,116-118)}$ there are limited applications of nitrogen nucleophiles. ${ }^{64)}$ This background led us to examine asymmetric allylic amination of 2-methoxycarbonyl 2-cyclohexenyl alcohol derivative 60 with benzylamine using our catalyst system (Table 9). The effect of the ligand structure revealed that the introduction of electron-donating groups onto the aromatic rings attached to the nitrogen atoms increases the enantioselectivity, and the 3,4-dimethoxy-type ligand $\left(S, R_{\mathrm{P}}\right)-\mathbf{1} \mathbf{j}$ was best for asymmetric induction. Moreover, enantioselectivity was increased when the reaction was

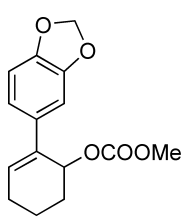

57
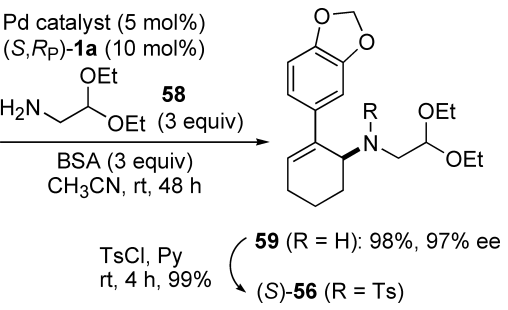

Chart 9. Catalytic Asymmetric Synthesis of $(S)-56$ performed at a lower temperature. Using $2 \mathrm{~mol} \%$ of Pd catalyst and $4 \mathrm{~mol} \%$ of $\left(S, R_{\mathrm{P}}\right)-\mathbf{1} \mathbf{j}$, cyclic product $(S)$-61a was obtained in $99 \%$ yield with $99 \%$ ee (entry 9 ).

The scope and limitations of different substrates were examined using the optimized reaction conditions (Table 10). When $2 \mathrm{~mol} \%$ of Pd catalyst and $4 \mathrm{~mol} \%$ of $\left(S, R_{\mathrm{P}}\right)-\mathbf{1} \mathbf{j}$ were used, asymmetric allylic amination of $\mathbf{6 0}$ using primary amines (entries $1-6$ ), a secondary amine (entry 7), and an aromatic amine (entry 8) proceeded efficiently to provide the corresponding products in excellent yield and enantiomeric excess. Other cyclic substrates with a five-membered ring and a seven-membered ring were also applicable to this reaction, affording the corresponding chiral allylic amines in $91 \%$ ee and $84 \%$ ee, respectively (entries 9,10 ). Furthermore, a substrate with a simple secondary amide, as well as the Weinreb amide-type substrate, could be utilized for this reaction system, giving the corresponding products in excellent yield and enantiomeric excess (entries 11,12). Similarly,

Table 9. Optimization of the Reaction Conditions

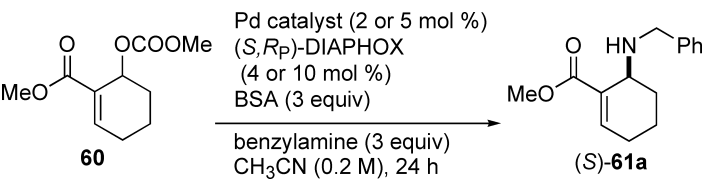

\begin{tabular}{cccccc}
\hline \hline Entry & DIAPHOX & $\begin{array}{c}\text { Pd cat. } \\
(\mathrm{mol} \%)\end{array}$ & $\begin{array}{c}\text { Temp. } \\
\left({ }^{\circ} \mathrm{C}\right)\end{array}$ & $\begin{array}{c}\text { Yield } \\
(\%)\end{array}$ & $\begin{array}{c}\text { ee } \\
(\%)\end{array}$ \\
\hline 1 & $\mathbf{1 a}$ & 5 & 4 & 91 & 87 \\
2 & $\mathbf{1 b}$ & 5 & 4 & 92 & 89 \\
3 & $\mathbf{1 c}$ & 5 & 4 & 97 & 83 \\
4 & $\mathbf{1 g}$ & 5 & 4 & 96 & 90 \\
5 & $\mathbf{1 h}$ & 5 & 4 & 99 & 71 \\
6 & $\mathbf{1 i}$ & 5 & 4 & 99 & 89 \\
7 & $\mathbf{1 j}$ & 5 & 4 & 99 & 94 \\
8 & $\mathbf{1 j}$ & 2 & 4 & 99 & 94 \\
9 & $\mathbf{1 j}$ & 2 & -30 & 99 & 99 \\
\hline
\end{tabular}

Table 10. Scope and Limitations

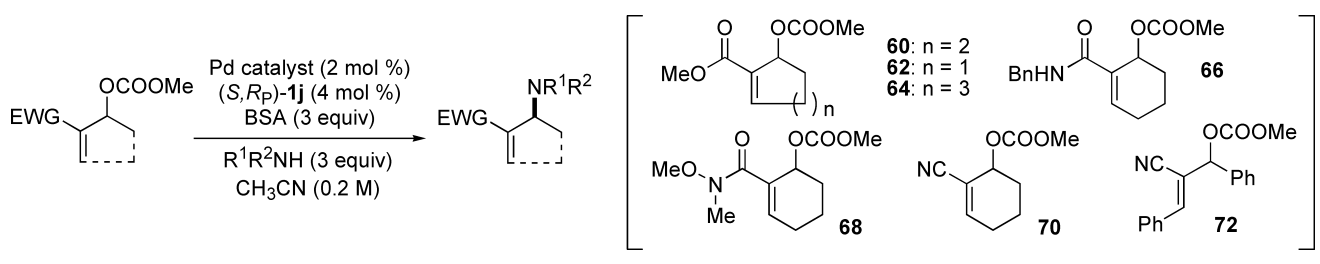

\begin{tabular}{|c|c|c|c|c|c|c|c|}
\hline Entry & Substrate & $\mathrm{R}^{1} \mathrm{R}^{2} \mathrm{NH}$ & Product & Temp. $\left({ }^{\circ} \mathrm{C}\right)$ & Time (h) & Yield (\%) & ee $(\%)$ \\
\hline 1 & 60 & Benzylamine & $61 \mathrm{a}$ & -30 & 24 & 99 & $99(S)$ \\
\hline 2 & 60 & 4-Methoxybenzylamine & $61 b$ & -30 & 24 & 99 & $97(S)$ \\
\hline 3 & 60 & Furfurylamine & $61 c$ & -30 & 24 & 99 & 98 \\
\hline 4 & 60 & Allylamine & 61d & -40 & 24 & 99 & 98 \\
\hline 5 & 60 & Isopropylamine & $61 \mathrm{e}$ & -30 & 24 & 92 & 99 \\
\hline 6 & 60 & $N^{\text {in }}$-Boc-tryptamine & $61 f$ & -30 & 24 & 97 & 96 \\
\hline 7 & 60 & Morpholine & $61 \mathrm{~g}$ & -10 & 15 & 98 & 99 \\
\hline $8^{a)}$ & 60 & $p$-Anisidine & $61 \mathrm{~h}$ & -30 & 47 & 99 & $94(S)$ \\
\hline $9^{a), b)}$ & 62 & Benzylamine & 63 & -40 & 18 & 81 & $91(S)$ \\
\hline $10^{a)}$ & 64 & Benzylamine & 65 & -40 & 18 & 99 & 84 \\
\hline 11 & 66 & Benzylamine & 67 & -30 & 48 & 94 & 98 \\
\hline $12^{a)}$ & 68 & Benzylamine & 69 & -30 & 32 & 98 & $99(S)$ \\
\hline $13^{c)}$ & 70 & Benzylamine & 71 & -40 & 18 & 99 & 95 \\
\hline 14 & 72 & Benzylamine & 73 & 4 & 24 & 96 & 89 \\
\hline
\end{tabular}

a) $\left(S, R_{\mathrm{P}}\right)$-1a was used. b) Dichloroethane was used as the solvent. c) $\left(S, R_{\mathrm{P}}\right)-\mathbf{1 g}$ was used. 

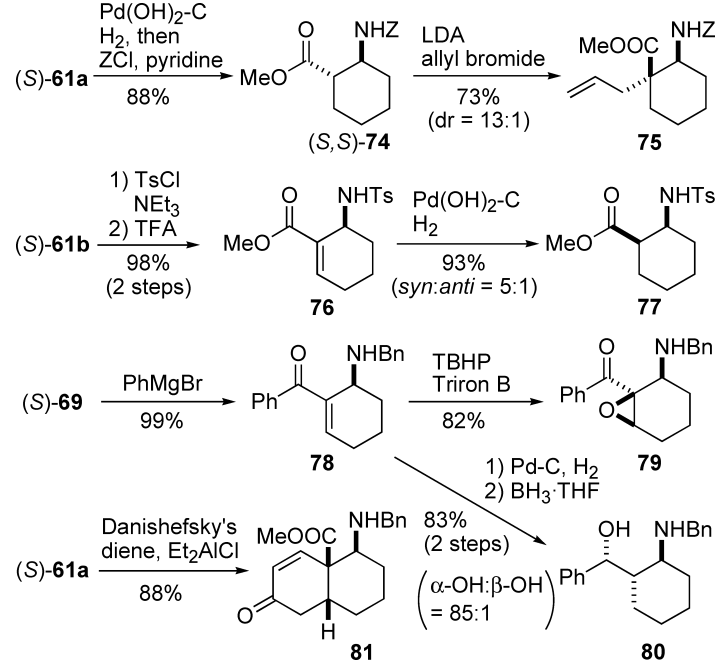

Chart 10. Diastereoselective Modifications of Aza-MBH Adducts

a reaction using a cyclic substrate with a nitrile group proceeded at $-40^{\circ} \mathrm{C}$ to provide the corresponding product in high enantiomeric excess (entry 13). In addition, asymmetric allylic amination of 1,3-diphenylallyl carbonate derivative $\mathbf{7 2}$ proceeded at $4{ }^{\circ} \mathrm{C}$ to provide the corresponding product in $89 \%$ ee (entry 14 ).

To demonstrate the usefulness of these chiral allylic amines, several diastereoselective modifications were performed (Chart 10). Chiral cyclic $\beta$-amino acids have gained much attention due to their increasing importance for the synthesis of $\beta$-peptides. ${ }^{19)}$ There are, however, few catalytic asymmetric synthetic methods. ${ }^{120,121)}$ Our synthesis started with $(S)$-61a and $(S)-61 b$. Both olefin hydrogenation and debenzylation of $(S)$-61a using $\mathrm{Pd}(\mathrm{OH})_{2}-\mathrm{C}$, followed by protection of the resulting free amine with a carbobenzyloxy $(Z)$ group, afforded the cyclic anti- $\beta$-amino acid derivative $(S, S)$ 74 in $88 \%$ yield as a nearly optically pure compound $(99 \%$ ee). In this hydrogenation, the reaction proceeded with complete diastereoselection, giving the anti-product exclusively. On the other hand, protection of $(S)-\mathbf{6 1 b}$ with a tosyl group, followed by treatment with trifluoroacetic acid, gave $\alpha, \beta$-unsaturated ester $\mathbf{7 6}$ in $98 \%$ yield without any noticeable loss of optical purity $(97 \%$ ee). This product could be transformed into the cyclic syn- $\beta$-amino acid derivative 77 with good diastereoselectivity (syn:anti=5:1). The usefulness of these compounds was further demonstrated. After the formation of lithium enolate of 74, diastereoselective alkylation was performed using allyl bromide as an electrophile, ${ }^{122)}$ affording the product with an all-carbon quaternary stereocenter in $73 \%$ yield with high diastereoselectivity $(\mathrm{dr}=13: 1)$. Weinreb amide-type adduct $(S)-69$ (99\% ee) reacted with a Grignard reagent at $-40{ }^{\circ} \mathrm{C}$ to provide the corresponding enone 78 in $99 \%$ yield $(99 \%$ ee). This enone could be converted into $\alpha, \beta$-epoxy ketone 79 (82\% yield) and 1,3-aminoalcohol 80 (83\% yield) in a highly diastereoselective manner. Moreover, Diels-Alder reaction of $(S)$-61a with the Danishefsky's diene proceeded in the presence of $\mathrm{Et}_{2} \mathrm{AlCl}$, giving the bicyclic product $\mathbf{8 1}$ in $88 \%$ yield as a single diastereomer.

3.4. Pd-Catalyzed Asymmetric Allylic Amination Using Aromatic Amine Nucleophiles ${ }^{123)}$ Although various nitrogen nucleophiles are available for Pd-catalyzed
Table 11. Optimization of the Reaction Conditions

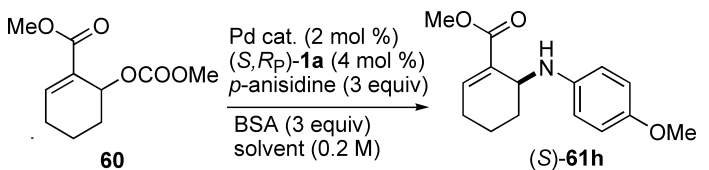

\begin{tabular}{cccccc}
\hline \hline Entry & Solvent & $\begin{array}{c}\text { Temp. } \\
\left({ }^{\circ} \mathrm{C}\right)\end{array}$ & $\begin{array}{c}\text { Time } \\
(\mathrm{h})\end{array}$ & $\begin{array}{c}\text { Yield } \\
(\%)\end{array}$ & $\begin{array}{c}\text { ee } \\
(\%)\end{array}$ \\
\hline 1 & $\mathrm{CH}_{3} \mathrm{CN}$ & 4 & 7 & 99 & 90 \\
2 & $\mathrm{CH}_{3} \mathrm{CH}_{2} \mathrm{CN}$ & 4 & 16 & 99 & 73 \\
3 & $\mathrm{CH}_{2} \mathrm{Cl}_{2}$ & 4 & 24 & 98 & 78 \\
4 & $\mathrm{DMF}_{5}$ & 4 & 4 & 99 & 90 \\
6 & $\mathrm{CH}_{3} \mathrm{CN}$ & -30 & 47 & 99 & 94 \\
& $\mathrm{DMF}$ & -30 & 48 & 99 & 95 \\
\hline
\end{tabular}

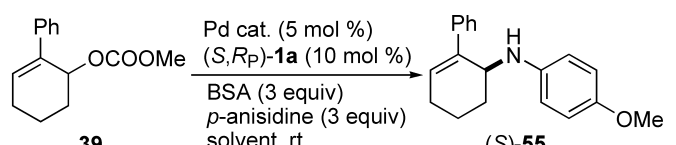

(S)-55

in $\mathrm{CH}_{3} \mathrm{CN}: 17 \mathrm{~h}, 8 \%, 95 \%$ ee
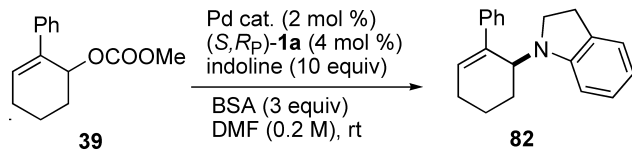

82

$3 \mathrm{~h}, 94 \%, 99 \%$ ee

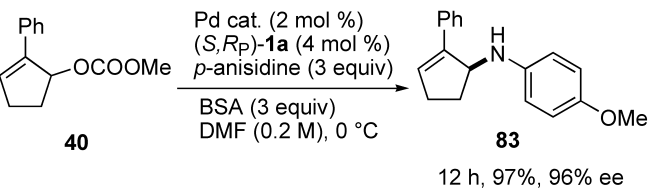

Chart 11. Asymmetric Allylic Amination of Cyclic Substrates Using Aromatic Amine Nucleophiles

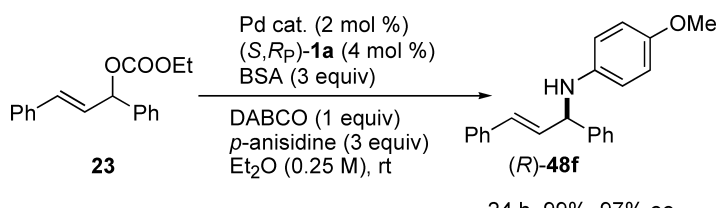

$24 \mathrm{~h}, 99 \%, 97 \%$ ee

Chart 12. Asymmetric Allylic Amination of $\mathbf{2 3}$ with $p$-Anisidine

asymmetric allylic aminations, aromatic amines are not commonly used in these reactions, ${ }^{124)}$ probably due to the lower nucleophilicity of aromatic amines compared with that of aliphatic amines or stabilized anionic nitrogen nucleophiles derived from aromatic amines. Actually, asymmetric allylic amination of 7, 23, and 39 using $p$-anisidine did not proceed under the optimized conditions for asymmetric allylic amination with aliphatic amines (Table 7, entries 6, 7, and Table 8, entry 12). As shown in Table 10 , cyclic substrate 60 exhibited much higher reactivity toward $p$-anisidine, providing the corresponding product $(S)-\mathbf{6 1 h}$ in $99 \%$ yield with $94 \%$ ee. Therefore, asymmetric allylic amination of $\mathbf{6 0}$ using $p$-anisidine was selected for initial optimization of the reaction conditions (Table 11). Examination of the solvent effect revealed that the reaction medium dramatically affected reactivity, as well as enantioselectivity, and the best reactivity was obtained when DMF was used as the solvent (entry 4). Although the enhanced reactivity in DMF was not observed 
at a lower temperature, the reaction proceeded in $48 \mathrm{~h}$ to afford $(S)-61$ h in $99 \%$ yield with $95 \%$ ee (entry 6 ).

Based on these results, we examined asymmetric allylic amination of 2-phenylcyclohexenyl alcohol derivative 39 with $p$-anisidine using DMF as the solvent (Chart 11). The reaction rate was remarkably enhanced when the reaction was performed in DMF using $5 \mathrm{~mol} \%$ of Pd catalyst and $10 \mathrm{~mol} \%$ of $\left(S, R_{\mathrm{P}}\right)-\mathbf{1 a}$, and the corresponding product $(S)-\mathbf{5 5}$ was obtained in $99 \%$ yield with $97 \%$ ee. Indoline, a secondary aromatic amine, was also applicable to this reaction, affording the corresponding product $\mathbf{8 2}$ with excellent enantioselectivity. In addition, asymmetric allylic amination of 2phenyl-substituted cyclopentenol-type substrate 40 was examined using DMF as the solvent, providing the corresponding product 83 in $97 \%$ yield with $96 \%$ ee. On the other hand, asymmetric allylic amination of $\mathbf{2 3}$ with $p$-anisidine was sluggish even with use of DMF as the solvent $(5 \mathrm{~mol} \%$ of the catalyst, $24 \mathrm{~h}, 30 \%$ yield, $74 \%$ ee). Further optimizations of the reaction conditions revealed that there was a remarkable increase in the reactivity by the addition of base such as DABCO or $N, N$-dimethylpiperazine. Finally, the best result was obtained when the reaction was performed in $\mathrm{Et}_{2} \mathrm{O}$ using 1 eq of DABCO as the additive (99\% yield, 97\% ee) (Chart 12).

\section{Ir-Catalyzed Asymmetric Allylic Substitution Reac- tions}

Phosphites and phosphoroamidites are effective ligands in Ir-catalyzed allylic substitution reactions of terminal allylic electrophiles to give branched products. ${ }^{125-127)}$ As shown in Chart 5, DIAPHOX 1a is activated by $N, O$-bis(trimethylsilyl)acetamide (BSA)-induced tautomerization to afford trivalent phosphorus compound $\mathbf{1 3}$, which functions as the actual ligand. The diamidophosphite structure of $\mathbf{1 3}$ led us to hypothesize that the present ligand system could be extended to Ir-catalyzed asymmetric allylic substitution reactions.

4.1. Ir-Catalyzed Asymmetric Allylic Amination ${ }^{128)}$ We first examined asymmetric allylic amination of cinnamyl carbonate 84 with benzylamine (Table 12). ${ }^{129-138)}$ No reaction occurred when $1 \mathrm{~mol} \%$ of chloro(1,5-cyclooctadiene)-
iridium(I) dimer $\left([\operatorname{Ir}(\operatorname{cod}) \mathrm{Cl}]_{2}\right)$ and $4 \mathrm{~mol} \%$ of $\left(S, R_{\mathrm{P}}\right)-\mathbf{1 a}$ $(\mathrm{Ir}: \mathbf{1 a}=1: 2)$ were used in $\mathrm{CH}_{2} \mathrm{Cl}_{2}$ at room temperature (entry 1). In contrast, when $1 \mathrm{~mol} \%$ of $[\operatorname{Ir}(\operatorname{cod}) \mathrm{Cl}]_{2}$ and $2 \mathrm{~mol} \%$ of $\left(S, R_{\mathrm{P}}\right)-\mathbf{1 a}(\operatorname{Ir}: \mathbf{1 a}=1: 1)$ were used, branched product 85a was obtained in $63 \%$ ee, even though the yield was only $10 \%$ (entry 2 ). In this reaction, the formation of linear product 85a' was not observed in ${ }^{1} \mathrm{H}-\mathrm{NMR}$ analysis of the crude sample. Encouraged by this result, we investigated the effect of the addition of sodium salts. Both the reactivity and enantioselectivity were dramatically affected by the counter anion of sodium salts, and best reactivity was obtained when hexafluorophosphate salt was used. Although there was a slight decrease in the enantiomeric excess $(59 \%$ ee), branched product 85a was obtained in 99\% yield using $5 \mathrm{~mol}^{\%}$ of $\mathrm{NaPF}_{6}$ (entry 6). ${ }^{139)}$ We next attempted to improve the enantioselectivity by tuning the structure of DIAPHOX (entries 7-12). Detailed investigations into the ligand structure indicated that introduction of substituents onto the aromatic rings attached to the nitrogen atoms tended to improve the enantioselectivity. The best result was obtained using chiral diaminophosphine oxide $\left(S, R_{\mathrm{P}}\right)-\mathbf{1} \mathbf{i}$, which possessed a $t$ $\mathrm{Bu}$ substituent on the para-position of the aromatic rings, and the enantiomeric excess of $\mathbf{8 5 a}$ increased to $92 \%$ ee when the reaction was performed at $-20^{\circ} \mathrm{C}$ (entry 12). On the other hand, when the reaction was performed using $\left(S, R_{\mathrm{P}}\right)-21$, a diaminophosphine oxide without a nitrogen atom on the sidearm, there was no significant change in the enantioselectivity compared with that obtained using $\left(S, R_{\mathrm{P}}\right) \mathbf{- 1 a}$ (entry $6 v s$. entry 11). This result indicates that this series of diaminophosphine oxides coordinates to the Ir metal in a monodentate manner through the phosphorus atom.

The scope and limitations of different substrates were examined using the optimized conditions (Table 13). When $2 \mathrm{~mol} \%$ of Ir catalyst, $2 \mathrm{~mol} \%$ of $\left(S, R_{\mathrm{P}}\right)-\mathbf{1 i}$, and $5 \mathrm{~mol} \%$ of $\mathrm{NaPF}_{6}$ were used, asymmetric allylic amination of 84 with primary amines and an $\alpha$-branched primary amine proceeded at $-20^{\circ} \mathrm{C}$ to provide the corresponding branched allylic amines 85a - c in good yield and in high enantioselectivity (entries 1-3). In contrast, there was a decreased enantioselectivity when morpholine was used as a nucleophile (entry

Table 12. Optimization of the Reaction Conditions

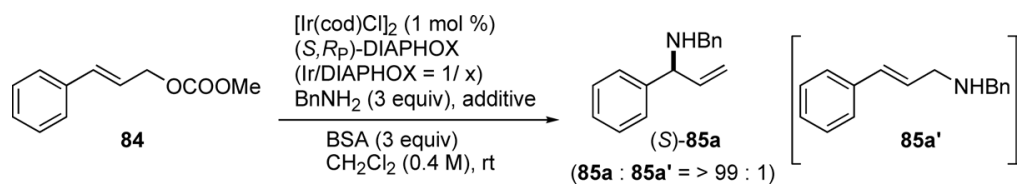

\begin{tabular}{|c|c|c|c|c|c|c|}
\hline Entry & $x$ & DIAPHOX & Additive (mol\%) & Time (h) & Yield (\%) & ee $(\%)$ \\
\hline 1 & 2 & $1 \mathbf{a}$ & - & 22 & No reaction & - \\
\hline 2 & 1 & $1 \mathbf{a}$ & - & 22 & 10 & 63 \\
\hline 3 & 1 & $1 \mathbf{a}$ & $\mathrm{NaI}(10)$ & 22 & 16 & 60 \\
\hline 4 & 1 & 1a & $\mathrm{NaBF}_{4}(10)$ & 22 & 70 & 66 \\
\hline 5 & 1 & $1 \mathbf{a}$ & $\mathrm{NaPF}_{6}(10)$ & 7 & 86 & 58 \\
\hline 6 & 1 & $1 \mathbf{a}$ & $\mathrm{NaPF}_{6}(5)$ & 7 & 99 & 59 \\
\hline 7 & 1 & $1 g$ & $\mathrm{NaPF}_{6}(5)$ & 19 & 51 & 60 \\
\hline 8 & 1 & $1 \mathrm{~h}$ & $\mathrm{NaPF}_{6}(5)$ & 19 & 10 & 73 \\
\hline 9 & 1 & $\mathbf{1 i}$ & $\mathrm{NaPF}_{6}(5)$ & 19 & 93 & 86 \\
\hline 10 & 1 & $\mathbf{1 j}$ & $\mathrm{NaPF}_{6}(5)$ & 19 & 25 & 68 \\
\hline 11 & 1 & 22 & $\mathrm{NaPF}_{6}(5)$ & 19 & 99 & 58 \\
\hline $12^{a)}$ & 1 & $\mathbf{1 i}$ & $\mathrm{NaPF}_{6}(5)$ & 48 & 96 & 92 \\
\hline
\end{tabular}

a) Reaction was performed at $-20^{\circ} \mathrm{C}$. 
Table 13. Scope and Limitations

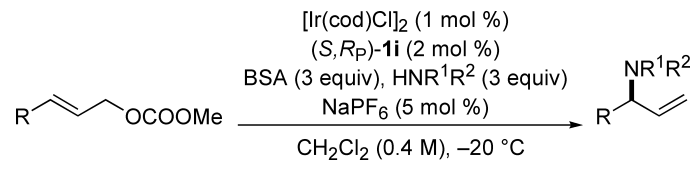

\begin{tabular}{|c|c|c|c|c|c|c|c|}
\hline Entry & Substrate & Amine & Product & Time (h) & Yield (\%) & Ratio (b/l) & ee $(\%)$ \\
\hline 1 & 84: $\mathrm{R}=$ phenyl & Benzylamine & $85 a$ & 48 & 96 & $>99 / 1$ & $92(S)$ \\
\hline 2 & 84: $\mathrm{R}=$ phenyl & Frufurylamine & $85 b$ & 48 & 95 & $>99 / 1$ & 94 \\
\hline 3 & 84: $\mathrm{R}=$ phenyl & Isopropylamine & $85 \mathrm{c}$ & 60 & 98 & $>99 / 1$ & 92 \\
\hline $4^{a)}$ & 84: $\mathrm{R}=$ phenyl & Morpholine & $85 d$ & 24 & 96 & $>99 / 1$ & 65 \\
\hline 5 & 86: $\mathrm{R}=4$-methoxyphenyl & Benzylamine & 87 & 24 & 99 & $>99 / 1$ & 91 \\
\hline 6 & 88: $\mathrm{R}=4$-chlorophenyl & Benzylamine & 89 & 48 & 99 & $>99 / 1$ & 94 \\
\hline 7 & 90: $\mathrm{R}=3$-fluorophenyl & Benzylamine & 91 & 48 & 92 & $>99 / 1$ & 95 \\
\hline 8 & 92: $\mathrm{R}=2$-methoxyphenyl & Benzylamine & 93 & 48 & 97 & $>99 / 1$ & 93 \\
\hline $9^{b)}$ & 94: $\mathrm{R}=1$-naphthyl & Benzylamine & 95 & 60 & 98 & $>99 / 1$ & 87 \\
\hline $10^{b)}$ & 96: $\mathrm{R}=2$-naphthyl & Benzylamine & 97 & 60 & 97 & $>99 / 1$ & 87 \\
\hline 11 & 98: $\mathrm{R}=2$-furanyl & Benzylamine & 99 & 36 & 94 & $>99 / 1$ & 88 \\
\hline 12 & 100: $\mathrm{R}=\mathrm{CH}_{2} \mathrm{CH}_{2} \mathrm{Ph}$ & Benzylamine & 101 & 60 & 74 & c) & 68 \\
\hline
\end{tabular}
tained

a) Reaction was performed at room temperature. b) Reactions were performed at $-5^{\circ} \mathrm{C} . \quad$ c) $8 \%$ of linear-linear product and $5 \%$ of branched-linear product were ob-

Table 14. Optimization of the Reaction Conditions

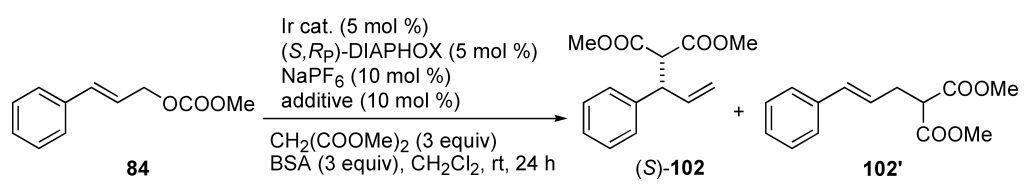

\begin{tabular}{|c|c|c|c|c|c|c|}
\hline Entry & Additive & DIAPHOX & Conc. (M) & Yield (\%) & Ratio $\left(\mathbf{1 0 2} / \mathbf{1 0 2}^{\prime}\right)$ & ee $(\%)$ \\
\hline 1 & - & $1 \mathbf{a}$ & 0.4 & 29 & $97 / 3$ & 75 \\
\hline 2 & $\mathrm{LiCl}$ & 1a & 0.4 & 95 & $97 / 3$ & 72 \\
\hline 3 & LiOAc & 1a & 0.4 & 71 & $95 / 5$ & 90 \\
\hline 4 & LiOAc & 1a & 0.5 & 73 & $96 / 4$ & 88 \\
\hline 5 & LiOAc & 1a & 0.25 & 90 & $95 / 5$ & 88 \\
\hline 6 & LiOAc & $1 b$ & 0.25 & 54 & $95 / 5$ & 57 \\
\hline 7 & LiOAc & 1c & 0.25 & 69 & $96 / 4$ & 74 \\
\hline 8 & LiOAc & 1d & 0.25 & 92 & $99 / 1$ & 90 \\
\hline 9 & LiOAc & 1e & 0.25 & 92 & $97 / 3$ & 82 \\
\hline 10 & LiOAc & 1f & 0.25 & 28 & $95 / 5$ & 81 \\
\hline 11 & LiOAc & $\mathbf{1 i}$ & 0.25 & 78 & $90 / 10$ & 45 \\
\hline
\end{tabular}

4). Asymmetric allylic amination of various terminal allylic carbonates was also examined using benzylamine as the nucleophile. Aromatic substituents with electron-donating and electron-withdrawing functionalities were tolerant to this reaction, giving the products with good to high enantioselectivity (entries 5-8). Terminal allylic carbonates with a naphthyl substituent (entries 9, 10) or a heteroaromatic substituent (entry 11) were also applicable to this reaction, affording the corresponding product with good enantioselectivity. In addition, asymmetric allylic amination of $\mathbf{1 0 0}$, a substrate with an alkyl substituent, was examined using $2 \mathrm{~mol} \%$ of the catalyst, giving the corresponding product $\mathbf{1 0 1}$ in $74 \%$ yield with $68 \%$ ee, accompanied by $8 \%$ of linear-linear product and $5 \%$ of branched-linear product (entry 11).

4.2. Ir-Catalyzed Asymmetric Allylic Alkylation ${ }^{140)}$ The success of the asymmetric allylic amination led us to examine asymmetric allylic alkylation using the Ir-DIAPHOX catalyst system. $^{141-155)}$ Optimizations of reaction conditions were performed using asymmetric allylic alkylation of 84 with dimethyl malonate using $\left(S, R_{\mathrm{P}}\right)$-1a (Table 14). Although no reaction occurred when $2.5 \mathrm{~mol} \%$ of chloro(1,5-cyclooc-
tadiene)iridium(I) dimer $\left([\operatorname{Ir}(\operatorname{cod}) \mathrm{Cl}]_{2}\right)$ and $5 \mathrm{~mol} \%$ of $\left(S, R_{\mathrm{P}}\right)$ $1 \mathbf{a}(\operatorname{Ir} / \mathbf{1} \mathbf{a}=1 / 1)$ were used, the same reaction proceeded in the presence of $10 \mathrm{~mol}^{\%}$ of $\mathrm{NaPF}_{6}$, affording branched product (S)-102 with high regioselectivity $(29 \%$ yield, 102/102' $=$ $97 / 3,75 \%$ ee) (entry 1 ). The addition of LiCl remarkably increases both reactivity and enantioselectivity in the Ir-catalyzed asymmetric allylic alkylation. ${ }^{142,143,147)}$ Thus we investigated the effect of adding lithium salt. Although reactivity was significantly improved when $\mathrm{LiCl}$ was used as the additive, there was a slight decrease in the enantioselectivity (entry 2). Both reactivity and enantioselectivity, on the other hand, were affected by the addition of LiOAc. Further optimization with regard to the reaction concentration resulted in the formation of branched product $(S)$-102 in good yield $\left(90 \%\right.$ yield, $\left.\mathbf{1 0 2} / \mathbf{1 0 2}^{\prime}=95 / 5\right)$ with $88 \%$ ee (entry 5$)$. The increased reactivity under the diluted reaction condition is likely related to the solubility of LiOAc in $\mathrm{CH}_{2} \mathrm{Cl}_{2}$. We next attempted to improve the regioselectivity and enantioselectivity by tuning the structure of DIAPHOX (entries 6-11). Studies of the effect of substituents on the aromatic rings revealed that $\left(S, R_{\mathrm{P}}\right)-\mathbf{1 d}$, which possesses a 3-biphenyl group at 


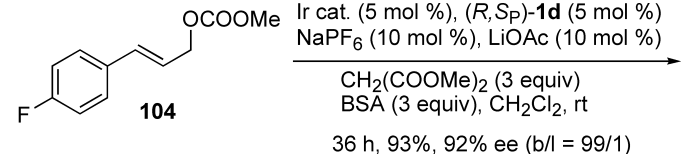

36 h, $93 \%, 92 \%$ ee $(b / l=99 / 1)$

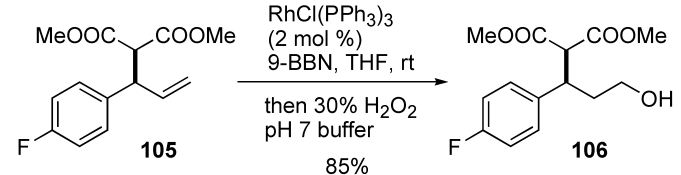

$85 \%$
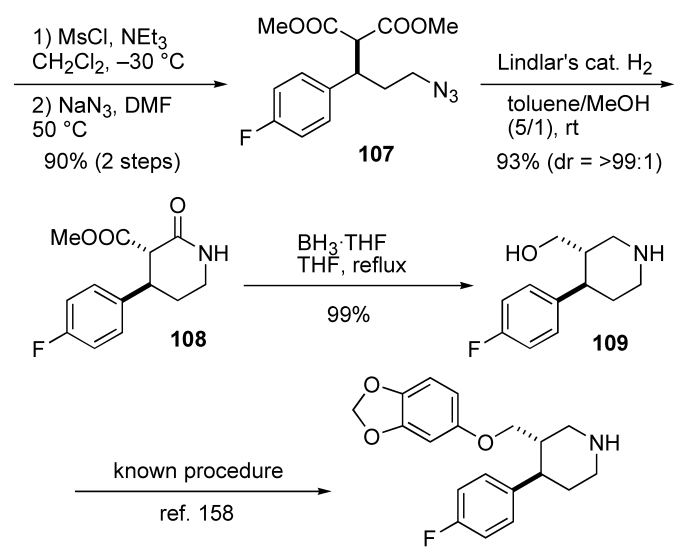

(-)-Paroxetine (103)

Chart 13. Enantioselective Synthesis of (-)-Paroxetine

the benzylic moiety, was best for asymmetric induction $(90 \%$ ee), giving the branched product $(S)-\mathbf{1 0 2}$ in good yield with excellent regioselectivity $\left(93 \%\right.$ yield, $\left.\mathbf{1 0 2} / \mathbf{1 0 2}^{\prime}=99 / 1\right)$ (entry 11).

The developed reaction system was successfully applied to the enantioselective synthesis of (-)-paroxetine 103 (Chart 13). ${ }^{156-163)}$ First, Ir-catalyzed asymmetric allylic alkylation of 104 with dimethyl malonate was performed using $\left(R, S_{\mathrm{P}}\right)$ 1d, affording 105 in $90 \%$ yield (branched/linear=99/1) with $92 \%$ ee. Hydroboration of the olefin with 9-BBN in the presence of Wilkinson's catalyst, followed by work-up with hydrogen peroxide, gave $\mathbf{1 0 6}$ in $85 \%$ yield. ${ }^{164)}$ After conversion of the hydroxyl group to an azide group (90\% yield), $\mathbf{1 0 7}$ was treated with Lindlar's catalyst in toluene/MeOH (5/1) under hydrogen atmosphere to provide lactam 108 in $93 \%$ yield as a single diastereomer (anti/syn $=>99 / 1)$. Subsequent reduction of 108 with $\mathrm{BH}_{3} \cdot$ THF complex gave $(3 S, 4 R)-(-)$ $\mathbf{1 0 9}$ in $99 \%$ yield. The known intermediate $\mathbf{1 0 9}$ can be converted into 103 using the reported procedure. ${ }^{158)}$

\section{Conclusion}

Transition metal-catalyzed reactions using secondary phosphine oxides or their equivalent have attracted attention in these past several years due to the air and moisture stability of pentavalent phosphine oxides. Application to asymmetric catalysis using chiral phosphine oxides is, however, still limited. We developed a new class of P-chirogenic phosphine oxides based on a chiral diamine framework: P-chirogenic diaminophosphine oxides: DIAPHOXs. These pentavalent phosphorus compounds, the preligands, reacted with BSA to provide the trivalent diamidophosphite species, which functioned as the actual ligands. Asymmetric allylic alkylation, asymmetric allylic amination, and enantioselective construction of quaternary carbons were investigated using the Pd- and Ir-DIAPHOX catalyst systems, affording various chiral compounds with good to excellent enantioselectivity. In addition, the developed reactions were successfully applied to catalytic asymmetric syntheses of biologically active compounds. We believe that DIAPHOX ligands have great potential and will be applied to a variety of transition metal-mediated asymmetric reactions. As that occurs, development of new conditions for activating DIAPHOXs other than the BSA-induced $\mathrm{P}(\mathrm{V})$ to $\mathrm{P}(\mathrm{III})$ tautomerization will become an important key.

Acknowledgements These works were carried out under the direction of Prof. Yasumasa Hamada at Chiba University. I would like to express my sincere appreciation for his kind and valuable advice during these studies. The research reviewed in this paper was possible only through the dedication, enthusiasm, and creativity of all the co-workers, whose names are acknowledged on the publications from our laboratory cited here. These works were supported by Grant-in Aid for Encouragement of Young Scientist (A), and Grant-in Aid for Scientific Research on Priority Areas, Chemistry of Concerto Catalysis, from the Ministry of Education, Culture, Sports, Science, and Technology of Japan. I am also grateful for financial support received from Inoue Research Award for Young Scientist, Banyu Award in Synthetic Organic Chemistry, and Daiichi-Sankyo Award in Synthetic Organic Chemistry.

\section{References and Notes}

1) For a general review, see: Ojima I., "Catalytic Asymmetric Synthesis II,” Wiley-VCH, New York, 2000.

2) Barton D., Ollis W. D., "Comprehensive Organic Chemistry," Vol. 2, Part 10, ed. by Sutherland I. O., Pergammon Press, Oxford, 1979.

3) For a review, see: Dubrovina N. V., Börner A., Angew. Chem. Int. Ed., 43, 5883-5886 (2004).

4) For a review, see: Ackermann L., Synthesis, 2006, 1557-1571 (2006).

5) For a review, see: Ackermann L., Synlett, 2007, 507-526 (2007).

6) Ghaffar T., Parkins A. W., Tetrahedron Lett., 36, 8657-8660 (1995).

7) Cobley C. J., van den Heuvel M., Abbadi A., de Vries J. G., Tetrahedron Lett., 41, 2467-2470 (2000).

8) Li G. Y., Angew. Chem. Int. Ed., 40, 1513-1516 (2001).

9) Yang W., Wang Y., Corte J. R., Org. Lett., 5, 3131-3134 (2003).

10) Wolf C., Lerebours R., Org. Lett., 6, 1147-1150 (2004).

11) Ackermann L., Born R., Angew. Chem. Int. Ed., 44, 2444-2447 (2005).

12) Ackermann L., Born R., Spatz J. H., Meyer D., Angew. Chem. Int. Ed., 44, 7216-7219 (2005).

13) Gavryushin A., Kofink C., Manolikakes G., Kochel P., Org, Lett., 7, $4871-4874$ (2005)

14) Ackermann L., Althammer A., Org. Lett., 8, 3457-3460 (2006).

15) Ackermann L., Gschrei C. J., Althammer A., Riederer M., Chem. Commun., 2006, 1419-1421 (2006).

16) Lerebours R., Wolf C., J. Am. Chem. Soc., 128, 13052-13053 (2006).

17) Ackermann L., Org. Lett., 7, 3123-3125 (2005).

18) Ackermann L., Althammer A., Born R., Angew. Chem. Int. Ed., 45, 2619-2622 (2006).

19) Jiang X.-b., Minnaard A. J., Hessen B., Feringa B. L., Duchateau A. L. L., Andrien J. G. O., Booger J. A. F., de Vries J. G., Org. Lett., 5, 1503-1506 (2003)

20) Jiang X.-b., van den Berg M., Minnaard A. J., Feringa B. L., de Vries J. G., Tetrahedron: Asymmetry, 15, 2223-2229 (2004).

21) Dai W.-M., Yeung K. K. Y., Leung W. H., Haynes R. K., Tetrahedron: Asymmetry, 14, 2821-2826 (2003).

22) Bigeault J., Giordano L., Buono G., Angew. Chem. Int. Ed., 44, 4753-4757 (2005).

23) Drabowicz J., Lyzwa P., Omelanczuk J., Pietrusiewicz K. M., Mikolajajczyk M., Tetrahedron: Asymmetry, 10, 2757-2763 (1999).

24) Haynes R. K., Au-Yeung Y.-L., Chen W.-K., Lam W.-L., Li Z.-Y., Yeung L.-L., Chen A. S. C., Li P., Koen M., Mitchell C. R., Vonwiller S. C., Eur. J. Org. Chem., 2000, 3205-3216 (2000).

25) Leyris A., Nuel D., Giordano L., Achard M., Buono G., Tetrahedron Lett., 46, 8677-8680 (2005).

26) For a review, see: Trost B. M., Crawley M. L., Chem. Rev., 103, 
$2921-2943$ (2003)

27) For a review, see: Lu Z., Ma S., Angew. Chem. Int. Ed., 47, 258-297 (2008).

28) For a review, see: Nemoto T., Hamada Y., Chem. Rec., 7, 150-158 (2007).

29) Nemoto T., Matsumoto T., Masuda T., Hitomi T., Hatano K., Hamada Y., J. Am. Chem. Soc., 126, 3690-3691 (2004).

30) Nemoto T., Masuda T., Matsumoto T., Hamada Y., J. Org. Chem., 70, 7172 - 7178 (2005)

31) For a review, see: El Gihani M. T., Heaney H., Synthesis, 1998, 357 375 (1998).

32) For a review, see: Christoffers J., Mann A., Angew. Chem. Int. Ed., 40, 4591-4597 (2001)

33) For a review, see: Shibasaki M., Erasmus V. M. Ohshima T., $A d v$ Synth. Catal., 346, 1533-1552 (2004).

34) For a review, see: Trost B. M., Jiang C., Synthesis, 2006, 369-396 (2006).

35) For a review, see: Shibasaki M., Kanai M., Org. Biomol. Chem., 5, 2027-2039 (2007).

36) For a representative example, see: Hayashi T., Kanehira K., Tsuchiya H., Kumada M., J. Chem. Soc. Chem. Commun., 1982, 1162-1164 (1982).

37) For a representative example, see: Sawamura M., Nagata H., Sakamoto H., Ito Y., J. Am. Chem. Soc., 114, 2586-2592 (1992).

38) For a representative example, see: Sawamura M., Sudoh M., Ito Y., $J$. Am. Chem. Soc., 118, 3309-3310 (1996).

39) For a representative example, see: Trost B. M., Radinov R., Grenzer E. M., J. Am. Chem. Soc., 119, 7879-7880 (1997).

40) For a representative example, see: Nakoji M., Kaneyama T., Okino T., Takemoto Y., J. Org. Chem., 67, 7418-7423 (2002).

41) For a representative example, see: Behenna D. C., Stoltz B. M., J. Am. Chem. Soc., 126, $15044-15045$ (2004).

42) For a representative example, see: Trost B. M., Xu J., J. Am. Chem. Soc., 127, 2846-2847 (2005)

43) For a representative example, see: Trost B. M., Bream R. N., Xu J., Angew. Chem. Int. Ed., 45, 3109-3112 (2006).

44) For a representative example, see: Fukuda Y., Kondo K., Aoyama T., Tetrahedron Lett., 48, 3389-3391 (2007).

45) Nemoto T., Fukuda T., Matsumoto T., Hitomi T., Hamada Y., Adv. Synth. Catal., 347, 1504-1506 (2005).

46) For a review on secondary ligand substrate interaction, see: Sawamura M., Ito Y., Chem. Rev., 92, 857-871 (1992).

47) For a review on secondary ligand substrate interaction, see: Börner A., Eur. J. Inorg. Chem., 2001, 327-337 (2001).

48) Nemoto T., Jin L., Nakamura H., Hamada Y., Tetrahedron Lett., 47 $6577-6581$ (2006)

49) Genet J. P., Grisoni S., Tetrahedron Lett., 29, 4543-4546 (1988).

50) Rieck H., Helmchen G., Angew. Chem. Int. Ed. Engl., 34, 26872689 (1995)

51) Uozumi Y., Suzuka T., J. Org. Chem., 71, 8644-8646 (2006)

52) Maki K., Kanai M., Shibasaki M., Tetrahedron, 63, 4250-4257 (2007).

53) For a representative synthesis, see: Wikström H., Sanshez D., Lindberg P., Hacksell U., Arvidsson L.-E., Johansson A. M., Thorberg S.O., Nilsson J. L. G., Svensson K., Hjorth S., Clark D., Carlsson A., J. Med. Chem., 27, 1030-1036 (1984).

54) For a representative synthesis, see: Amat M., Cantó M., Llor N., Escolano C., Molins E., Espinosa E., Bosch J., J. Org. Chem., 67, 5343-5351 (2002).

55) Brice J. L., Meerdink J. E., Stahl S. S., Org. Lett., 6, 1845-1848 (2004).

56) For a representative synthesis, see: Corey E. J., Zhang F.-Y., Org. Lett., 2, 4257-4259 (2000).

57) For a representative synthesis, see: Belda O., Lundgren S., Moberg C., Org. Lett., 5, 2275-2278 (2003).

58) For a representative synthesis, see: Okino T., Hoashi Y., Furukawa T., Xu X., Takemoto Y., J. Am. Chem. Soc., 127, 119-125 (2005).

59) For a representative synthesis, see: Carpes M. J. S., Correia C. R. D., Tetrahedron Lett., 43, 741-744 (2002).

60) Jin L., Nemoto T., Nakamura H., Hamada Y., Tetrahedron: Asymmetry, 19, 1106-1113 (2008).

61) For an example using carbon nucleophiles, see: Hamada Y., Sakaguchi K., Hatano K., Hara O., Tetrahedron Lett., 42, 1297-1299 (2001).
62) For an example using carbon nucleophiles, see: Stang A. Q., Helmchen G., Helv. Chim. Acta, 88, 2738-2746 (2005).

63) For an example using nitrogen nucleophiles, see: Mori M., Kuroda S., Zhang C.-S., Sato Y., J. Org. Chem., 62, 3263-3270 (1997).

64) For an example using nitrogen nucleophiles, see: Trost B. M., Oslob J. D., J. Am. Chem. Soc., 121, 3057-3064 (1999).

65) For an example using nitrogen nucleophiles, see: Mori M., Nishimata T., Nagasawa Y., Sato Y., Adv. Synth. Catal., 343, 34-36 (2001).

66) For an example using nitrogen nucleophiles, see: Mori M., Nakanishi D., Kajishima D., Sato Y., J. Am. Chem. Soc., 125, 9801-9807 (2003).

67) For an example using oxygen nucleophiles, see: Trost B. M., Machacek M. R., Tsui H. C., J. Am. Chem. Soc., 127, 7014-7024 (2005).

68) For an example using oxygen nucleophiles, see: Trost B. M., Tang W., Toste F. D., J. Am. Chem. Soc., 127, 14785-14803 (2005).

69) Nemoto T., Harada T., Matsumoto T., Hamada Y., Tetrahedron Lett., 48, 6304-6307 (2007)

70) For a review on asymmetric synthesis of quaternary $\alpha$-amino-acid derivatives, see: Cativiela C., Díaz-de-Villegas M. D., Tetrahedron: Asymmetry, 9, 3517-3599 (1998).

71) For a review on asymmetric synthesis of quaternary $\alpha$-amino-acid derivatives, see: Cativiela C., Díaz-de-Villegas M. D., Tetrahedron: Asymmetry, 11, 645-732 (2000).

72) For a review on asymmetric synthesis of quaternary $\alpha$-amino-acid derivatives, see: Park K.-H., Kurth M. J., Tetrahedron, 58, 86298659 (2002).

73) For a review on asymmetric synthesis of quaternary $\alpha$-amino-acid derivatives, see: Gröger H., Chem. Rev., 103, 2795-2828 (2003).

74) For a recent leading reference of catalytic asymmetric synthesis of quaternary $\alpha$-amino acid derivatives, see: Vachal P., Jacobsen E. N., Org. Lett., 2, 867-870 (2000).

75) For a recent leading reference of catalytic asymmetric synthesis of quaternary $\alpha$-amino acid derivatives, see: Funabashi K., Ratni H., Kanai M., Shibasaki M., J. Am. Chem. Soc., 123, 10784-10785 (2001).

76) For a recent leading reference of catalytic asymmetric synthesis of quaternary $\alpha$-amino acid derivatives, see: Masumoto S., Usuda H., Suzuki M., Kanai M., Shibasaki M., J. Am. Chem. Soc., 125, 5634 5635 (2003).

77) For a recent leading reference of catalytic asymmetric synthesis of quaternary $\alpha$-amino acid derivatives, see: Sabby S., Bella M., Jørgensen K. A., J. Am. Chem. Soc., 126, 8120-8121 (2004).

78) For a recent leading reference of catalytic asymmetric synthesis of quaternary $\alpha$-amino acid derivatives, see: Zhuang W., Saaby S., Jørgensen K. A., Angew. Chem., Int. Ed., 43, 4476-4478 (2004).

79) For a recent leading reference of catalytic asymmetric synthesis of quaternary $\alpha$-amino acid derivatives, see: Kitamura M., Shirakawa S., Maruoka K., Angew. Chem., Int. Ed., 44, 1549-1551 (2005).

80) For a recent leading reference of catalytic asymmetric synthesis of quaternary $\alpha$-amino acid derivatives, see: Liu X., Li H., Deng L., Org. Lett., 7, 167-169 (2005).

81) For a recent leading reference of catalytic asymmetric synthesis of quaternary $\alpha$-amino acid derivatives, see: Ooi T., Miki T., Maruoka K., Org. Lett., 7, 191-193 (2005).

82) For a recent leading reference of catalytic asymmetric synthesis of quaternary $\alpha$-amino acid derivatives, see: Suri J. T., Steiner D. D., Barbas C. F., III, Org. Lett., 7, 3885-3888 (2005).

83) For a recent leading reference of catalytic asymmetric synthesis of quaternary $\alpha$-amino acid derivatives, see: Balskus E. P., Jacobsen E. N., J. Am. Chem. Soc., 128, 6810-6812 (2006).

84) For a recent leading reference of catalytic asymmetric synthesis of quaternary $\alpha$-amino acid derivatives, see: Mashiko T., Hara K. Tanaka D., Fujiwara Y., Kumagai N., Shibasaki M., J. Am. Chem. Soc., 129, 11342-11343 (2007).

85) For a recent leading reference of catalytic asymmetric synthesis of quaternary $\alpha$-amino acid derivatives, see: Chen Z., Morimoto $H$., Matsunaga S., Shibasaki M., J. Am. Chem. Soc., 130, 2170-2171 (2008).

86) For a recent leading reference of catalytic asymmetric synthesis of quaternary $\alpha$-amino acid derivatives, see: Singh A., Johnston J. N., $J$. Am. Chem. Soc., 130, 5866-5867 (2008).

87) Kuwano R., Ito Y., J. Am. Chem. Soc., 121, 3236-3237 (1999).

88) Ogasawara M., Ngo H., Sakamoto T., Takahashi T., Org. Lett., 7, 
$2881-2884(2005)$

89) $\alpha$-Acetoamido $\beta$-keto phosphonates as the nucleophiles, see: Kuwano R., Nishio, R., Ito Y., Org. Lett., 1, 837-839 (1999).

90) Azlactones are also useful nucleophiles for providing access to chiral quaternary $\alpha$-amino acid derivatives, see: Trost B. M., Ariza X., Angew. Chem. Int. Ed., 36, 2635-2637 (1997).

91) Azlactones are also useful nucleophiles for providing access to chiral quaternary $\alpha$-amino acid derivatives, see: Trost B. M., Dogra K., $J$. Am. Chem. Soc., 124, 7256-7257 (2002).

92) For a review, see: Trost B. M., Chem. Pharm. Bull., 50, 1-14 (2002).

93) For a representative example, see: Hayashi T., Yamamoto A., Ito Y., Nishioka E., Miura H., Yanagi K., J. Am. Chem. Soc., 111, 63016311 (1989).

94) For a representative example, see: Trost B. M., Bunt R. C., J. Am Chem. Soc., 116, 4089-4090 (1994).

95) For a representative example, see: Evans D. A., Campos K. R., Tedrow J. S., Michael F. E., Gagné M. R., J. Org. Chem., 64, 2994 2995 (1999).

96) For a representative example, see: You S.-L., Zhu X.-Z., Lou Y.-M. Hou X.-L., Dai L.-X., J. Am. Chem. Soc., 123, 7471-7472 (2001)

97) For a representative example, see: Zablocka M., Koprowski M., Donnadieu B., Majoral J.-P., Achard M., Buono G., Tetrahedron Lett., 44 2413-2415 (2003).

98) For a representative example, see: Uozumi Y., Tanaka H., Shibatomi K., Org. Lett., 6, 281-283 (2004).

99) For a representative example, see: Faller J. W., Wilt J. C., Org. Lett., 7, 633-636 (2005)

100) For a review, see: Helmchen G., Dahnz A., Dübon P., Schelwies M. Weihofen R., Chem. Commun., 2007, 675-691 (2007).

101) For an example using a Ru catalyst, see: Matsushima Y., Onitsuka K., Kondo T., Mitsudo T., Takahashi S., J. Am. Chem. Soc., 123, 1040510406 (2001)

102) For an example using a Ni catalyst, see: Bekowitz D. B., Maiti G. Org. Lett., 6, 2661-2664 (2004).

103) Nemoto T., Masuda T., Akimoto Y., Fukuyama T., Hamada Y., Org. Lett., 7, 4447-4450 (2005).

104) We speculate that coordination of $\mathrm{CH}_{3} \mathrm{CN}$ to palladium metal might prevent catalyst deactivation by competitive coordination of the product, resulting in the higher reactivity compared with the cases of other solvents.

105) Nishimata T., Sato Y., Mori M., J. Org. Chem., 69, 1837-1843 (2004).

106) Nemoto T., Fukuyama T., Yamamoto E., Tamura S., Fukuda T., Matsumoto T., Akimoto Y., Hamada Y., Org. Lett., 9, 927-930 (2007).

107) For a review, see: Basavaiah D., Rao A. J., Satyanarayana T., Chem Rev., 103, 811-891 (2003).

108) For an representative example, see: Shi M., Xu Y.-M., Angew. Chem. Int. Ed., 41, 4507-4510 (2002).

109) For an representative example, see: Shi M., Chen L.-H., Chem. Commun., 2003, 1310-1311 (2003).

110) For an representative example, see: Kawahara S., Nakano A., Esumi T., Iwabuchi Y., Hatakeyama S., Org. Lett., 5, 3103-3105 (2003).

111) For an representative example, see: Balan D., Adolfsson H., Tetrahe dron Lett., 44, 2521-2524 (2003).

112) For an representative example, see: Raheen I. T., Jacobsen E. N., Adv. Synth. Catal., 347, 1701-1708 (2005).

113) For an representative example, see: Matsui K., Takizawa S., Sasai H. J. Am. Chem. Soc., 127, 3680-3681 (2005).

114) For an representative example, see: Shi M., Ma G.-N., Gao J., J. Org. Chem., 72, 9779—9781 (2007).

115) For an representative example, see: Takizawa S., Matsui K., Sasai H. J. Synth. Org. Chem. Jpn., 65, 1089-1098 (2007).

116) Trost B. M., Tsui H.-C., Toste F. D., J. Am. Chem. Soc., 122, 3534 3535 (2000)

117) Trost B. M., Thiel O. R., Tsui H.-C., J. Am. Chem. Soc., 124 11616-11617 (2002)

118) Trost B. M., Thiel O. R., Tsui H.-C., J. Am. Chem. Soc., 125, 13155-13164 (2003)

119) For a review, see: Cheng R. P., Gellman S. H., DeGrado W. F., Chem Rev., 101, 3219-3232 (2001).

120) Tang W., Wu S., Zhang X., J. Am. Chem. Soc., 125, 9570-9571 (2003).

121) Mita T., Fujimori I., Wada R., Wen J., Kanai M., Shibasaki M., J. Am. Chem. Soc., 127, 11252-11253 (2005).
122) Seebach D., Estermann H., Tetrahedron Lett., 28, 3103-3106 (1987)

123) Nemoto T., Tamura S., Sakamoto T., Hamada Y., Tetrahedron Asymmetry, 19, 1751-1759 (2008).

124) Dong Y., Teesdale-Spittle P., Hoberg J. O., Tetrahedron Lett., 46 $353-355$ (2005)

125) For the pioneering work on Ir-catalyzed allylic substitutions, see Takeuchi R., Kashio M., Angew. Chem. Int. Ed. Engl., 36, 263-265 (1997).

126) For the pioneering work on Ir-catalyzed allylic substitutions, see Takeuchi R., Kashio M., J. Am. Chem. Soc., 120, 8647-8655 (1998)

127) For the pioneering work on Ir-catalyzed allylic substitutions, see Takeuchi R., Ue N., Tanabe K., Yamashita K., Shiga N., J. Am. Chem. Soc., 123, 9525-9534 (2001).

128) Nemoto T., Sakamoto T., Matsumoto T., Hamada Y., Tetrahedron Lett., 47, 8737-8740 (2006).

129) For a representative example of Ir-catalyzed asymmetric allylic amination, see: Ohmura T., Hartwig J. F., J. Am. Chem. Soc., 124, $15164-15165$ (2002)

130) For a representative example of Ir-catalyzed asymmetric allylic amination, see: Kiener C. A., Shu C., Incarvito C., Hartwig J. F., J. Am Chem. Soc., 125, 14272-14273 (2003).

131) For a representative example of Ir-catalyzed asymmetric allylic amination, see: Shu C., Leiner A., Hartwig J. F., Angew. Chem. Int. Ed., 43, 4797-4800 (2004)

132) For a representative example of Ir-catalyzed asymmetric allylic amination, see: Tissot-Croset K., Polet D., Alexakis A., Angew. Chem Int. Ed., 43, 2426-2428 (2004).

133) For a representative example of Ir-catalyzed asymmetric allylic amination, see: Lipowsky G., Helmchen G., Chem. Commun., 2004, 896-897 (2004).

134) For a representative example of Ir-catalyzed asymmetric allylic amination, see: Miyabe H., Matsumura A., Moriyama K., Takemoto Y. Org. Lett., 6, 4631-4634 (2004).

135) For a representative example of Ir-catalyzed asymmetric allylic amination, see: Weihohen R., Dahnz A., Tverskoy O., Helmchen G., Chem. Commun., 2005, 3541-3543 (2005).

136) For a representative example of Ir-catalyzed asymmetric allylic amination, see: Polet D., Alexakis A., Org. Lett., 7, 1621-1624 (2005).

137) For a representative example of Ir-catalyzed asymmetric allylic amination, see: Weihohen R., Tverskoy O., Helmchen G., Angew. Chem. Int. Ed., 45, 5546-5549 (2006).

138) For a representative example of Ir-catalyzed asymmetric allylic amination, see: Pouy M. J., Leitner A., Weix D. J., Ueno S., Hartwig J. F., Org. Lett., 9, 3949-3952 (2007).

139) Although the role of hexafluorophosphate anion is unkown, we speculate that a cationic iridium complex might be formed by the anion exchange between hexafluorophosphate ion and a coordinated species around the Ir metal, resulting in the increased reactivity.

140) Nemoto T., Sakamoto T., Fukuyama T., Hamada Y., Tetrahedron Lett., 48, 4977-4981 (2007).

141) For a representative example of Ir-catalyzed asymmetric allylic alkylation, see: Janssen J. P., Helmchen G., Tetrahedron Lett., 38 8025-8026 (1997).

142) For a representative example of Ir-catalyzed asymmetric allylic alkylation, see: Bartels A., Helmchen G., Chem. Commun., 1999, $741-742$ (1999).

143) For a representative example of Ir-catalyzed asymmetric allylic alkylation, see: Fuji K., Kinoshita N., Tanaka K., Kawabata T., Chem. Commun., 1999, 2289-2290 (1999).

144) For a representative example of Ir-catalyzed asymmetric allylic alkylation, see: Kanayama T., Yoshida K., Miyabe H., Takemoto Y. Angew. Chem. Int. Ed., 42, 2054-2056 (2003).

145) For a representative example of Ir-catalyzed asymmetric allylic alkylation, see: Kanayama T., Yoshida K., Miyabe H., Kimachi T., Takemoto Y., J. Org. Chem., 68, 6197-6201 (2003).

146) For a representative example of Ir-catalyzed asymmetric allylic alkylation, see: Kinoshita N., Marx K. H., Tanaka K., Tsubaki K., Kawabata T., Yoshikai N., Nakamura E., Fuji K., J. Org. Chem., 69, 7960 -7964 (2004)

147) For a representative example of Ir-catalyzed asymmetric allylic alkylation, see: Alexakis A., Polet D., Org. Lett., 6, 3529-3532 (2004).

148) For a representative example of Ir-catalyzed asymmetric allylic alky- 
lation, see: Lipowsky G., Miller N., Helmchen G., Angew. Chem. Int $E d ., 43,4595-4597$ (2004).

149) For a representative example of Ir-catalyzed asymmetric allylic alkylation, see: Streiff S., Welter C., Schelwiss M., Lipowsky G., Miller N., Helmchen G., Chem. Commun., 2005, 2957-2959 (2005).

150) For a representative example of Ir-catalyzed asymmetric allylic alkylation, see: Graening T., Hartwig J. F., J. Am. Chem. Soc., 127, 17192-17193 (2005)

151) For a representative example of Ir-catalyzed asymmetric allylic alkylation, see: Polet D., Alexakis A., Tissot-Croset K., Corminboeuf C., Ditrich K., Chem. Eur. J., 12, 3596-3609 (2006).

152) For a representative example of Ir-catalyzed asymmetric allylic etherification, see: Shu C., Hartwig J. F., Angew. Chem. Int. Ed., 43, 4794-4797 (2004).

153) For a representative example of Ir-catalyzed asymmetric allylic etherification, see: Lyothier I., Defieber C., Carreira E. M., Angew. Chem. Int. Ed., 45, 6204-6207 (2006).

154) For a representative example of Ir-catalyzed asymmetric allylic etherification, see: Kimura M., Uozumi Y., J. Org. Chem., 72, 707-714 (2007).

155) For a representative example of Ir-catalyzed asymmetric allylic etherification, see: Ueno S., Hartwig J. F., Angew. Chem. Int. Ed., 47, 1928-1931 (2008)
156) For a catalytic asymmetric synthesis of paroxetine, see: Senda $T$., Ogasawara M., Hayashi T., J. Org. Chem., 66, 6852-6856 (2001).

157) For a catalytic asymmetric synthesis of paroxetine, see: Taylor M. S., Jacobsen E. N., J. Am. Chem. Soc., 125, 11204-11205 (2003).

158) For a catalytic asymmetric synthesis of paroxetine, see: Hughes G., Kimura M., Buchwald S. L., J. Am. Chem. Soc., 125, 11253-11258 (2003).

159) For a catalytic asymmetric synthesis of paroxetine, see: Brandau S., Landa A., Franzén J., Marigo M., Jørgensen K. A., Angew. Chem. Int. Ed., 45, 4305-4309 (2006).

160) For a catalytic asymmetric synthesis of paroxetine, see: Koech P. K., Krische M. J., Tetrahedron, 62, 10594-10602 (2006).

161) For a catalytic asymmetric synthesis of paroxetine, see: Ito M., Sakaguchi A., Kobayashi C., Ikariya T., J. Am. Chem. Soc., 129, 290-291 (2007).

162) For a catalytic asymmetric synthesis of paroxetine, see: Bower J. F., Riis-Johannessen T., Szeto P., Whitehead A. J., Gallagher T., Chem. Commun., 2007, 728-730 (2007).

163) For a catalytic asymmetric synthesis of paroxetine, see: Hynes P. S., Stupple P. A., Dixon D. J., Org. Lett., 10, 1389-1391 (2008).

164) Evans D. A., Fu G. C., Hoveyda A. H., J. Am. Chem. Soc., 114 $6671-6679(1992)$. 